\title{
ESPACIOS NATURALES PROTEGIDOS, RETO DEMOGRÁFICO Y TURISMO. EL EJEMPLO DE LA RESERVA DE LA BIOSFERA Y PARQUE NACIONAL DE MONFRAGÜE (EXTREMADURA, ESPAÑA)
}

\author{
Felipe Leco Berrocal* \\ Universidad de Extremadura \\ http://orcid.org/0000-0002-3372-4748 \\ Ana Beatriz Mateos Rodríguez** \\ Universidad de Extremadura \\ https://orcid.org/0000-0002-3850-0399
}

\section{RESUMEN}

Los espacios naturales protegidos son uno de los recursos más demandados desde el punto de vista turístico. Esta investigación analiza las relaciones causa-efecto que ha tenido la declaración de Monfragüe como Reserva de la Biosfera y Parque Nacional en el comportamiento demográfico, económico y turístico del territorio que comprende. Desde una metodología cualitativa, apoyado en el análisis de fuentes estadísticas, se concluye que las expectativas depositadas en el turismo no han conseguido frenar la despoblación ni potenciar la diversificación económica.

Palabras clave: Reserva de la Biosfera de Monfragüe; crisis demográfica; turismo; sostenibilidad.

\section{Protected natural spaces, tourism and demographic challenge. Monfragüe's (Extre- madura, Spain) Biosphere Reserve and National Park as an example}

Protected natural areas are one of the most demanded resources from the tourist point of view. This research analyses the cause-effect relationships that the declaration of Monfragüe as a Biosphere Reserve and National Park has had on the demographic, economic and tourist

Fecha de recepción: 2 de septiembre de 2020

Fecha de aceptación: 12 de noviembre de 2020.

* Instituto de Investigación en Patrimonio. Universidad de Extremadura. Avda. de la Universidad, s/n. 10003 CÁCERES (España). E-mail: fleco@unex.es

** Instituto de Investigación en Desarrollo Sostenible. Universidad de Extremadura. Avda. de la Universidad, s/n. 10003 CÁCERES (España).E-mail: abmateos@unex.es 
behaviour of the territory it encompasses. From a qualitative methodology, supported by the analysis of statistical sources, it is concluded that the expectations placed in tourism have not managed to halt depopulation or promote economic diversification.

Keywords: Monfragüe>s Biosphere Reserve; demographic crisis; tourism; sustainability.

\section{INTRODUCCIÓN}

Los espacios naturales protegidos se han ido configurando en las últimas décadas como recursos muy demandados por las sociedades actuales; recursos que llevan consigo unos indudables valores sociales y económicos asociados (Muñoz Flores, 2008; Corraliza et al., 2002). Algunos de esos recursos naturales acaban convirtiéndose en objetos de consumo (productos) materializados a través del turismo rural.

En la actualidad muchas de las estrategias de desarrollo territorial en la Unión Europea pasan por la diversificación económica de las zonas rurales, sobre todo las más deprimidas, proponiendo el turismo rural como un recurso estratégico que es necesario fortalecer para cambiar las dinámicas económicas y territoriales (Trillo Santamaría y Paül i Carril, 2018; Muñoz Flores, 2008; Soto Baquero et al., 2007; Delgadillo Macías, 2006; Vacas Guerrero, 2001).

Ahora bien, cualquier estrategia de desarrollo rural de base territorial no debe pasar por alto a los grupos humanos que habitan un territorio determinado. Por ello, es necesario conocer exhaustivamente la realidad geográfica desde un punto de vista social, económico, incluso cultural, para evaluar las posibilidades de éxito de las estrategias que puedan proponerse, de ahí la necesidad de evaluar previamente los recursos endógenos desde un punto de vista socioeconómico y demográfico, y desde la cohesión y participación social -partnership- (Hummel, 2001; Kóhler, 2001).

En este sentido, hay que tener en cuenta que la "protección de la naturaleza", a través de las distintas figuras existentes de espacios naturales protegidos, es un tema recurrente y paradójico para muchas poblaciones rurales donde se localizan estos espacios. Generalmente es una idea doblemente contradictoria, por un lado, porque estos grupos humanos tienen una mentalidad más conservadora (Alvarado, 2007) y, por otro lado, porque esa "demanda de naturaleza" tiene mayormente un origen netamente urbano.

Los espacios naturales protegidos son, en la mayoría de los casos, un excelente impulso de salida para el desarrollo de iniciativas de desarrollo rural basadas en el turismo como pieza clave para la diversificación económica (García Marín, 2011; Aparicio, 2004), ya que pueden aportar numerosos e innumerables beneficios (tangibles e intangibles) a estos territorios (Hidalgo-Fernández et al., 2013; Sotelo, 2006; Azqueta, 1997), incluso en aquellos territorios en los que se localizan espacios naturales protegidos que presentan unos bajos indicadores socioeconómicos (García et al., 2012; Pascual, 2007).

En los últimos años, el incremento de la movilidad de la población, el aumento del poder adquisitivo y la mayor disponibilidad del tiempo de ocio ha llevado consigo un aumento de la afluencia de visitantes en espacios naturales protegidos. Esta situación, al 
mismo tiempo, hace necesaria una planificación y una gestión adecuada de los recursos naturales y de las infraestructuras y equipamientos de los espacios naturales protegidos (Leco et al., 2015; Gómez Limón y García, 2014; Sowman, 1987; O’Reilly, 1986; Shelby \& Heberlein, 1986).

En este sentido, las Reservas Mundiales de la Biosfera (en adelante RB), son territorios propuestos por los Estados para que, si fuera el caso, fuesen reconocidos por el Programa Hombre y Biosfera (MaB) de la UNESCO. Los objetivos principales de las $R B$ se basan en la promoción del desarrollo sostenible de estos territorios (Cantos Mengs et al., 2010), siendo el turismo uno de sus referentes dentro de la diversificación económica para ese desarrollo. Las $R B$ son una buena oportunidad, quizás una de las últimas, para asegurar un mínimo impulso vital, a través de los recursos endógenos, naturales y culturales (Bilbao González y Díez Casero, 2010) para hacer frente al reto demográfico de la despoblación (Jurado Almonte y Pazos-García, 2016), del envejecimiento y la masculinización de la población rural (Pérez Díaz et al., 2012; Camarero, 2009; Barrientos Alfageme, 19791983; Gurría Gascón, 1981; García Zarza, 1977) o de la pérdida de las señas de identidad territorial con referencia en el paisaje y en los recursos naturales (Canales, Segrelles y Vera, 2012; Aparicio et al., 2012; Leco et al., 2012; Hernández, 2009).

Uniendo los objetivos del Programa MaB de la UNESCO junto con el turismo, como uno de los referentes del desarrollo sostenible, una de las estrategias que se están llevando a cabo en la Reserva de Mundial de la Biosfera de Monfragüe (en adelante RBM), territorio que ocupará nuestra investigación, es su adhesión a la Carta Europea del Turismo Sostenible para fijar una estrategia entre los gestores del espacio protegido y las empresas del sector turístico en materia de desarrollo de un turismo participado y sostenible, desde el punto de vista ecológico, sociocultural y económico (Gómez Limón y Múgica de la Guerra, 2007).

Desde esta perspectiva, el 30 de julio de 2009 se firmaron las bases, a través de un convenio entre la Diputación de Cáceres, la Junta de Extremadura, TURESPAÑA y la Asociación de Turismo de Monfragüe (ATUMON), para regular la ejecución del Plan de Competitividad Turística de la $R B M$, respondiendo al propósito de reequilibrio socioterritorial a nivel del turismo en la Comunidad Autónoma de Extremadura y a escala estatal. Fue en septiembre de 2011 cuando finalmente EUROPARC otorga al Parque la Carta Europea del Turismo Sostenible (https://www.miteco.gob.es/es/red-parques-nacionales/ nuestros-parques/monfrague/turismo-sostenible.aspx).

Este Plan de Competitividad Turística de la $R B M$ también responde a los muchos valores y elementos de patrimonialización que este territorio encierra y que ocupan un lugar destacado como productos turísticos de primera magnitud. Entre ellos destacan los recursos naturales: Monfragüe alberga cerca de 300 especies de vertebrados y una variedad asombrosa de ecosistemas (roquedos; riberas y láminas de agua; bosques y matorrales mediterráneos; dehesas y pastizales).

Dicho plan debía responder, en parte, a la pérdida constante de efectivos demográficos y sus consecuencias en la dinámica natural y espacial de la población en este territorio. Un problema que no es nuevo, al menos para la Geografía y para los geógrafos, tampoco es un problema afrontado y mucho menos es un problema resuelto. Y a todas luces, a pesar de los esfuerzos ímprobos de la administración en potenciar el "monocultivo" del turismo, 
muy especialmente en las áreas rurales y, sobre todo, en los espacios naturales protegidos, esta actividad económica ha sido incapaz de frenar por sí sola la despoblación y la pérdida de efectivos demográficos (Rodríguez, Larrubia y Sinoga, 2021; Maroto y Pinos, 2019; Labianca y Navarro, 2019) y mucho menos ejercer como foco para la localización de una adecuada oferta alojativa (Sánchez y Rengifo, 2016).

Quizás, por estas razones, las $R B$ pueden constituirse en una gran oportunidad para la diversificación económica pero mucho más allá del turismo. En 1977 fueron declaradas las primeras Reservas Mundiales de la Biosfera, a fecha de 2020 la red de RB sumaba 714 reservas, distribuidas en 129 países, 21 de ellas transfronterizas, siendo España con 52 el país con mayor número de ellas (Fuente: https://en.unesco.org/biosphere/wnbr), siendo su desarrollo espectacular en las últimas décadas, sólo entre 2016-2020 las declaraciones aumentaron en un $15,5 \%$.

La Comunidad Autónoma de Extremadura cuenta con tres $R B$ :

- Monfragüe. Declarada el 9 de julio de 2003 sobre un territorio de 116.160 ha. Engloba, total o parcialmente, un total de 14 términos municipales y una población que alcanzó un total de 12.267 habitantes en 2020.

- Tajo-Tejo Internacional. Declarada el 18 de marzo de 2016 sobre un territorio de 428.176 ha (259.643 ha en España y 168.533 ha en Portugal), para un total de 14 términos municipales extremeños y 12 freguesías portuguesas, y una población de 62.775 habitantes (13.435 habitantes en España en 2020 y 48.450 habitantes en Portugal en 2016).

- La Siberia. Declarada el 19 junio de 2019 por el Consejo Internacional de Coordinación (CIC) del Programa sobre el Hombre y la Biosfera (MaB). Se trata de la primera reserva de la provincia de Badajoz y tercera de la comunidad autónoma. Cuenta con una superficie de 155.717,49 ha. Está integrada por 11 términos municipales y una población que asciende a 10.652 habitantes en 2019.

\section{LOCALIZACIÓN Y CARACTERIZACIÓN GEOGRÁFICA}

"Monfragüe" fue declarado Reserva Mundial de la Biosfera (Programa MaB de la UNESCO) el día 9 de julio de 2003 "por ser un territorio representativo de la vegetación mediterránea en el que se ha mantenido una armonía entre los valores naturales y la progresiva y equilibrada intervención humana" (Fuente: http://rerb.oapn.es/redespanola-de-reservas-de-la-biosfera/reservas-de-la-biosfera-espanolas/mapa/monfrague/ descripcion-general).

Sin duda alguna, "este reconocimiento, y al mismo tiempo galardón, se debe fundamentalmente a la exquisita relación que el hombre ha mantenido con el medio a lo largo de la Historia, al tiempo hay que entender la declaración por los altos valores ambientales que mantiene, así como también por el grado de gestión y de actuación en el ámbito internacional que ya tenía el Parque Natural de Monfragüe" (Leco et al., 2010: 12).

Su ordenación viene dada por el Decreto 209/2009, de 4 de septiembre, que regula la organización y funcionamiento de la Reserva de la Biosfera de Monfragüe (DOE núm. 112, de 13 de junio de 2016) y por la Resolución de 16 de octubre de 2009, de la Dirección General del Medio Natural, por la que se ordena la publicación del Acuerdo nº 1/2009 
sobre aprobación del Reglamento de Régimen Interior del Consejo de Participación de la Reserva de la Biosfera de Monfragüe.

El territorio que ocupa la $R B M$ se localiza en la zona nororiental de la provincia de Cáceres (Figura 1). Está conformado básicamente por zonas de penillanura, riberos de los ríos Tajo y el Almonte, zonas aluviales del río Tiétar, donde aparecen magníficos ejemplos de bosque mediterráneo, pero también de vegetación riparia y "manchas" de matorral inaccesibles, todo ello coronado en las zonas más elevadas por un conjunto de sierras que, con disposición NO-SE, forman el denominado Arco de Cañaveral. Un territorio en el que los ríos Tajo y Tiétar se encajan "cortando los crestones cuarcíticos, y formando las conocidas portillas...La propia estructura geológica definida por el Sinforme de Monfragüe da lugar a un relieve de tipo apalachiano caracterizado por la existencia de una sucesión de crestas dibujadas por los materiales más resistentes (cuarcitas), y valles o depresiones sobre los materiales más erosionables (pizarras)" (http://extremambiente.juntaex.es).

El territorio que ocupa asciende a 116.160 ha, justamente el espacio que ocupa la Zona de Especial Protección de Aves (ZEPA) de Monfragüe y las Dehesas del entorno (Directiva CEE/409/79; declarada en 1991 y ampliada en 2004).

\section{Cuadro 1}

\section{APORTACIÓN SUPERFICIAL DE LOS MUNICIPIOS DE LA RBM}

\begin{tabular}{|l|r|r|r|r|}
\hline \multicolumn{1}{|c|}{ Municipio } & \multicolumn{1}{c|}{ (A) } & \multicolumn{1}{c|}{ (B) } & \multicolumn{1}{c|}{ (C) } & \multicolumn{1}{c|}{ (D) } \\
\hline Casas de Millán & $15.245,07$ & $3.835,00$ & 25,16 & 3,31 \\
\hline Casas de Miravete & $5.008,87$ & $4.967,01$ & 99,16 & 4,28 \\
\hline Casatejada & $11.111,95$ & 170,36 & 1,53 & 0,15 \\
\hline Deleitosa & $14.386,38$ & $1.296,56$ & 9,01 & 1,12 \\
\hline Higuera & $4.051,18$ & $1.970,58$ & 48,64 & 1,70 \\
\hline Jaraicejo & $17.800,78$ & $14.655,29$ & 82,33 & 12,63 \\
\hline Malpartida de Plasencia & $37.165,85$ & $16.752,18$ & 45,07 & 13,78 \\
\hline Mirabel & $4.911,60$ & $2.406,24$ & 48,99 & 2,07 \\
\hline Romangordo & $3.896,83$ & 766,62 & 19,67 & 0,66 \\
\hline Saucedilla & $6.003,29$ & 507,25 & 8,45 & 0,44 \\
\hline Serradilla & $25.918,84$ & $25.875,60$ & 99,83 & 22,32 \\
\hline Serrejón & $12.475,55$ & $11.373,09$ & 91,16 & 9,81 \\
\hline Toril & $14.961,46$ & $9.982,64$ & 66,72 & 8,60 \\
\hline Torrejón el Rubio & $22.205,08$ & $22.185,33$ & 99,91 & 19,14 \\
\hline Total RBM & $195.142,73$ & $116.743,75$ & 59,82 & 100,00 \\
\hline
\end{tabular}

Fuente: Leco Berrocal, F. et al., 2010: 15

$\mathrm{A}=$ Superficie total del término municipal (ha) y Área de Influencia Socioeconómica (territorio que aportan los términos municipales a la Reserva de la Biosfera y/o al Parque Nacional).

$\mathrm{B}=$ Superficie protegida del término municipal (ha).

$\mathrm{C}=$ Porcentaje de superficie protegida respecto al término municipal.

$\mathrm{D}=$ Porcentaje de superficie protegida respecto a la ZEPA "Monfragüe y las Dehesas del entorno" 


\section{LOCALIZACIÓN GEOGRÁFICA DE LA RESERVA DE LA BIOSFERA Y PAR- QUE NACIONAL DE MONFRAGÜE}

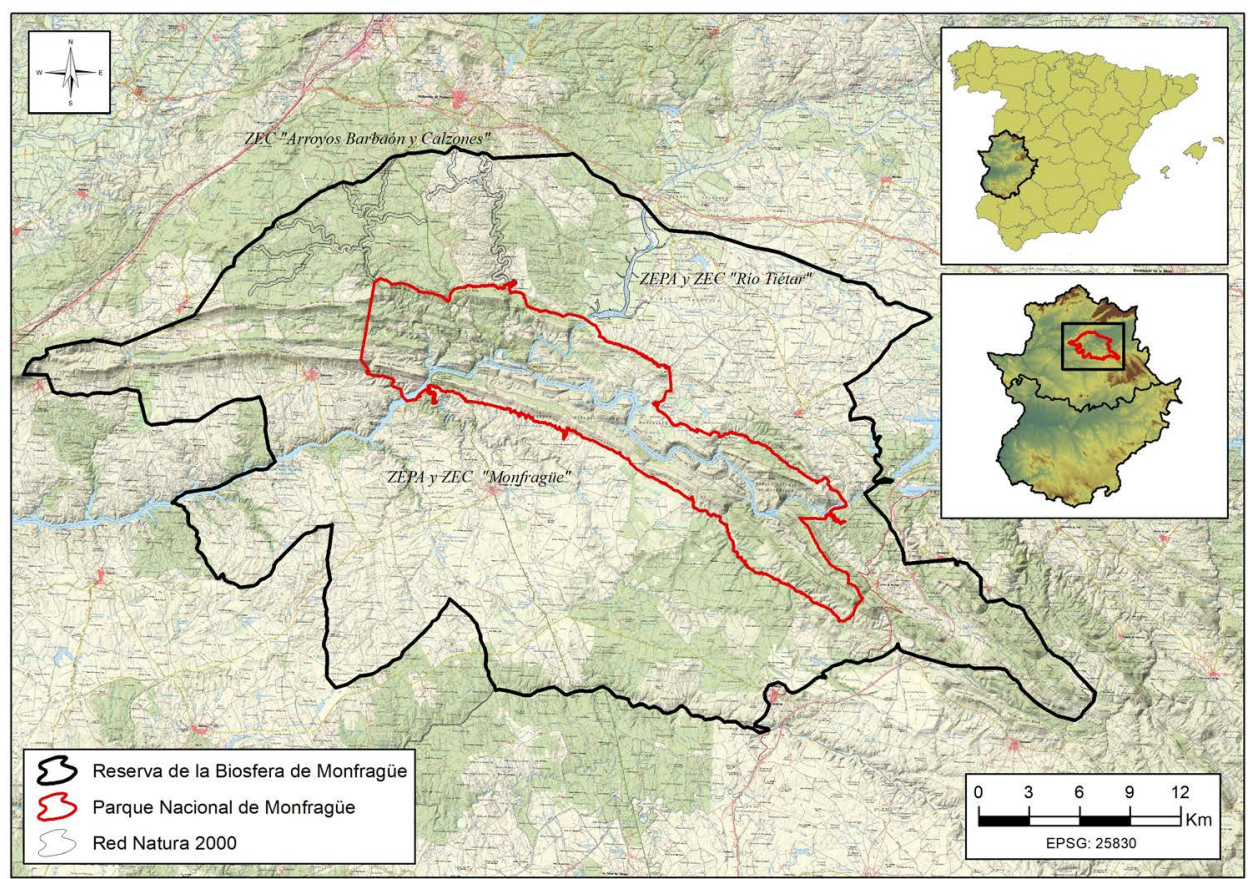

Fuente: Elaboración propia.

La $R B M$, además de tener esta declaración, alberga otras figuras de protección de la Naturaleza, bien de la Red Extremeña de Espacios Naturales Protegidos bien de la Red Natura 2000, que elevan la importancia de este territorio por sus valores naturales y culturales. Estas figuras se encuentran ordenadas por el Decreto 110/2015, de 19 de mayo, que regula la red ecológica europea Natura 2000 en Extremadura (DOE núm. 105, de 3 de Junio de 2015).

En el conjunto de la ZEPA destaca evidentemente la figura del Parque Nacional de Monfragüe (Ley 1/2007 de 2 de marzo. B.O.E. núm. 54 de 3 de marzo de 2007) que, entre otras ordenaciones, atiende al Decreto 75/2016, de 7 de junio, que modifica el Decreto 106/2007, de 22 de mayo, que regula la organización y funcionamiento del Parque Nacional de Monfragüe; el Decreto 186/2005, de 26 de julio, que aprueba el Plan de Ordenación de los Recursos Naturales del Parque Natural de Monfragüe y su Área de Influjo Socioeconómico (DOE núm. 3, de 3 de agosto de 2005) y, en último lugar, el Decreto 13/2014, de 18 de febrero, que aprueba el Plan Rector de Uso y Gestión del Parque Nacional de Monfragüe (DOE núm. 37, de 24 de febrero de 2014). 
El Parque Nacional de Monfragüe ocupa una extensión de 18.396 ha. Además de la categoría de Parque Nacional son varias las figuras de protección que coexisten en el territorio que abarca el Parque (18.396 ha) ya que, como señalábamos antes, también es ZEPA (Directiva CEE/409/79) y ZEC (Zonas Especial de Conservación) (Decreto 110/2015, de 19 de mayo, por el que se regula la red ecológica europea Natura 2000 en Extremadura; DOE núm. 105, de 3 de junio de 2015, pág. 19851) (Cuadro 2).

\section{Cuadro 2}

\section{ESPACIOS NATURALES PROTEGIDOS EN LA RBM}

\begin{tabular}{|l|l|r|}
\hline Nombre de la Figura & Tipo de Protección & Superficie (ha) \\
\hline Monfragüe y las Dehesas del entorno & ZEPA & $116.094,23$ \\
\hline Monfragüe & ZEC (1) & $114.818,53$ \\
\hline Río Almonte & ZEC & $9.409,48$ \\
\hline Río Tiétar & ZEC & $4.321,03$ \\
\hline Arroyos Barbaón y Calzones & ZEC (2) & $2.055,70$ \\
\hline Monfragüe & ZEC & $114.818,53$ \\
\hline
\end{tabular}

Fuente: adaptado de Leco Berrocal, F. et al., 2010: 13.

(1) La ZEC “Monfragüe" está íntegramente incluida en la ZEPA “Monfragüe y las Dehesas del entorno". Incluye el Parque Nacional de Monfragüe (18.396 ha).

(2) Igualmente incluye 1.276 ha de la ZEC “Arroyo Barbaón y Calzones”.

Por tanto, son varias las figuras de protección que se solapan en el territorio que ocupa la Reserva ello, pone de relieve la enorme importancia que tienen sus valores naturales y la diversidad de los mismos como ejemplo señero de protección de la Naturaleza y los recursos naturales en Extremadura.

Como en otras $R B$ existe una zonificación con superficies, valores ambientales, culturales y posibilidades de uso y actividad con una exacta diferenciación (Cuadro 3).

\section{Cuadro 3 \\ ZONIFICACIÓN DE LA RBM}

\begin{tabular}{|l|r|r|}
\hline \multicolumn{1}{|c|}{ Zona } & \multicolumn{1}{c|}{ Superficie (ha) } & \multicolumn{1}{c|}{ \% } \\
\hline Zona Núcleo & 12.830 & 11,05 \\
\hline Zona Tampón & 15.360 & 13,22 \\
\hline Zona de Transición & 87.970 & 75,73 \\
\hline Total & 116.160 & 100,00 \\
\hline
\end{tabular}

Fuente: Leco Berrocal, F. et al., 2010: 14.

La "zonas núcleo" son aquellas que están conformadas por las zonas riparias del Tajo y del Tiétar principalmente, están caracterizadas por su alto grado de conservación, siendo las áreas más importantes para la nidificación de las aves más representativas del Parque Nacional. La "zona tampón”, que envuelve a la anterior, alcanza el resto del territorio declarado como Parque Nacional, en ella suelen tener lugar el desarrollo de actividades 
relacionadas con el turismo, la investigación y la educación ambiental. Por último, la "zona de transición" se caracteriza por la presencia continua de grandes espacios adehesados de explotación ganadera extensiva y con la presencia casi testimonial de cinco núcleos de población que apenas alcanzan los 3.000 habitantes.

\section{OBJETIVOS Y METODOLOGÍA}

El objetivo esencial de esta investigación es la realización de un exhaustivo diagnóstico y análisis de la demografía y la economía del área que ocupa la $R B M$, así como de la aportación de la actividad turística en el desarrollo de este territorio desde 2003. Para ello, se parte de dos preguntas o hipótesis de trabajo, primera, ¿qué ha supuesto, desde el punto de vista demográfico y económico, para el territorio de "Monfragüe" la declaración de Reserva de la Biosfera y Parque Nacional? y, segunda, ¿las sinergias que conllevan las declaraciones de espacios naturales protegidos han conseguido paliar o cambiar las estructurales debilidades demográficas y económicas de este territorio?

Para tal objetivo se valorarán los siguientes indicadores demográficos y socioeconómicos:

- Evolución de la población absoluta.

- Dinámica natural.

- Dinámica espacial.

- Estructura demográfica.

- Otros indicadores demográficos: tasa de dependencia, índice de envejecimiento y sobreenvejecimiento, etc.

- Trabajadores y empresas por sectores de actividad, tasas de paro, renta disponible...

- Actividad turística: número de visitantes, demanda, oferta y ocupación alojativas.

El análisis de estas variables posibilitará evaluar los beneficios sociales y económicos que el nombramiento de la $R B M$ ha tenido en este territorio, ya que los ambientales no deben ponerse nunca en duda. Y ello debe hacerse pensando que el binomio "espacio natural protegido/turismo" se ha considerado, en muchas ocasiones, como la panacea o como la pócima mágica que llevaría a salvaguardar las debilitadas economías rurales de determinados territorios en los que la dimensión ambiental imponía unas estrategias territoriales diferentes (Vera y Espejo, 2006; Cebrián, 2008).

Este planteamiento previo de la investigación necesita resolver el dilema de cómo mantener el capital natural sin dejar de considerar el capital económico, al tiempo que el capital social se vea implicado en el desarrollo de su territorio y pueda beneficiarse de las dinámicas del mismo, siempre y cuando la resiliencia de este espacio protegido no se vea afectada negativamente en el tiempo (Leco, 2015: 237). Ciertamente, la resiliencia como objeto de estudio en el ámbito rural ya ha sido aplicado desde múltiples perspectivas del desarrollo sostenible (Walker et al., 2004; Plummer y Armitage, 2007; Wilson, 2010; McManus et al., 2012).

El territorio que ocupa la $R B M$ es pionero en Extremadura en lo relativo a la protección de los recursos naturales y culturales: el 23 de febrero de 1917 por Real Decreto la Portilla de Monfragüe fue declarada como "Sitio Notable"; en 1979 "Monfragüe" es declarado Parque Natural (Real Decreto 1927/1979, de 4 de abril, BOE núm. 188, de 7 de agosto de 
1979); en 2003 Reserva Mundial de la Biosfera y, por último, en 2007 Parque Nacional (Ley 1/2007 de 2 de marzo. BOE núm. 54 de 3 de marzo de 2007). De ahí que los conceptos conservación y desarrollo, asociados a este territorio, en ningún caso pueden ser considerados como conceptos antagónicos o contradictorios (Loscertales, 1999), puesto que es evidente la trayectoria protectora de este territorio y la búsqueda de la compatibilidad de este binomio para dinamizar el desarrollo local y sostenible.

Para alcanzar los objetivos anteriores se procedió a utilizar una metodología de tipo cualitativa no experimental (Kerlinger y Lee, 2002), como señala Briones se trata de "investigaciones ex post facto" (Briones, 1996: 46). Al mismo tiempo, se realizará un análisis descriptivo y cualitativo de las variables utilizadas. De esta manera se conseguirá aportar información completa y exacta de las variables demográficas y socioeconómicas del territorio de la $R B M$, al tiempo que los resultados del estudio podrán contribuir a realizar investigaciones posteriores o, si fuera el caso, a cambiar o apuntalar las estrategias de desarrollo de este territorio.

Para el análisis de los indicadores demográficos y económicos se tomó como fuentes de información primarias el Instituto Nacional de Estadística de España (http://www.ine. es) y el Instituto de Estadística de Extremadura (https://ciudadano.gobex .es/web/ieex).

Estas fuentes de información oficiales (la primera a nivel nacional, la segunda a nivel autonómico o regional) cuentan con series de datos suficientes como para afrontar los objetivos propuestos en este trabajo.

Por otro lado, la información correspondiente a las variables relacionadas con el sector turístico fue tomada del Observatorio de Turismo de Extremadura (https:/www.turismoextremadura.com), así como la Dirección General de Turismo de la Junta de Extremadura.

\section{RESULTADOS Y DISCUSIÓN}

\subsection{Evolución de la población}

Las características del paisaje de "Monfragüe”, especialmente su configuración orográfica y unas condiciones naturales idóneas, tales como la presencia de constante de cursos de agua, abrigos rocosos y vegetación frondosa y abundante, fueron una de las claves para acoger a poblaciones humanas ya entre comienzos del tercer milenio y mediados del primero aC (Epipaleolítico, Edad del Cobre y Edad del Bronce), seguro que, con toda probabilidad, procurarían su subsistencia y se establecerían temporalmente en las inmediaciones de los pastaderos y abrevaderos más frecuentados por los grandes herbívoros (Collado Giraldo et al., 2014).

A lo largo de la Historia esos grupos humanos, además de incorporar nuevas técnicas agrarias, acabaron por asentarse definitivamente en el entorno de "Monfragüe" facilitando, de este manera, por una parte una continuada transformación del paisaje en las zonas llanas y fértiles y, por otra parte, una mayor permanencia de las tierras más fragosas e inaccesibles que, en todo caso, se dedicaban a los aprovechamientos ganaderos y forestales (Leco et al., 2010). Las especiales dificultades orográficas de este territorio impidieron desde épocas tempranas una mayor intensidad de la ocupación humana pero, sin embargo, 
esta situación explica sobradamente la altísima biodiversidad y concentración de especies protegidas y vulnerables en este espacio natural protegido.

Esa débil intensidad de la ocupación de este territorio se traslada a nuestros días, ya que con una densidad poblacional que apenas supera los 6,3 habitantes $/ \mathrm{km}^{2}$ se encuentra por debajo del umbral que aplica la UE (8 habitantes $/ \mathrm{km}^{2}$ ) (Cuadro 4), como límite para que una región europea pueda optar a recibir fondos del Objetivo 6 de desarrollo regional en el Período 2014-2020, no en vano, como señala Molinero, "la densidad se ha convertido en el criterio clave para los geógrafos y para cualquier político y profesional de la Ordenación del Territorio" (Molinero, 2019: 27).

\section{Cuadro 4}

\section{POBLACIÓN Y DENSIDAD DEMOGRÁFICA MUNICIPAL, 2020}

\begin{tabular}{|l|r|r|r|}
\hline \multicolumn{1}{|c|}{ Municipios } & $\begin{array}{c}\text { Superficie } \\
\left(\mathbf{k m}^{2}\right)\end{array}$ & $\mathbf{N}^{\mathbf{0}}$ de Habitantes & \multicolumn{2}{c|}{$\begin{array}{c}\text { Densidad } \\
\left(\mathbf{h a b} / \mathbf{k m}^{2}\right)\end{array}$} \\
\hline Casas de Millán & 152,45 & 550 & 3,6 \\
\hline Casas de Miravete & 50,09 & 126 & 2,5 \\
\hline Casatejada & 111,12 & 1.344 & 4,8 \\
\hline Deleitosa & 143,86 & 687 & 2,7 \\
\hline Higuera & 40,51 & 110 & 2,6 \\
\hline Jaraicejo & 178,01 & 456 & 12,4 \\
\hline Malpartida de Plasencia & 371,66 & 4.602 & 13,5 \\
\hline Mirabel & 49,12 & 661 & 6,7 \\
\hline Romangordo & 38,97 & 263 & 14,2 \\
\hline Saucedilla & 60,03 & 852 & 5,8 \\
\hline Serradilla & 259,19 & 1.507 & 3,3 \\
\hline Serrejón & 124,76 & 410 & 1,0 \\
\hline Toril & 149,61 & 153 & 2,5 \\
\hline Torrejón el Rubio & 222,05 & 546 & 6,3 \\
\hline Reserva Biosfera & $1.951,43$ & 12.267 & \\
\hline
\end{tabular}

Fuente: INE y elaboración propia.

Otras circunstancias histórico-sociales, como el predominio de las grandes explotaciones adehesadas, de carácter ganadero y extensivo, "actuaron históricamente como factores de rechazo poblacional y sirvieron para animar el proceso emigratorio de la segunda mitad del siglo XX" (Leco et al., 2010: 21).

La población actual de la $R B M$ asciende a 12.267 habitantes, siendo Malpartida de Plasencia el municipio que concentra más del $37 \%$ de la población de este territorio con un total de 4.602 habitantes. Un total de once municipios no alcanzan los 1.000 habitantes, seis de ellos no llegan al umbral de 500 habitantes, valores que sitúan el grado de ruralidad (peso que tiene la población residente en núcleos con densidad inferior a los 10 habitantes $/ \mathrm{km}^{2}$ ) de la $R B M$ en un $40 \%$, muy por encima del grado de ruralidad medio de Extremadura que se sitúa en un $7,8 \%$. Estos valores sin duda ponen de manifiesto las 
especiales dificultades de este territorio para fijar población, aspecto que sólo consiguen los municipios de mayor densidad demográfica, especialmente Malpartida de Plasencia, mientras que la amenaza de la despoblación es un hecho en el resto de municipios.

No en vano, la pérdida de efectivos demográficos es una constante desde 1950 (fecha en la que se alcanzó el techo demográfico con 31.110 habitantes) hasta la actualidad. La revisión padronal de 2020 arroja una población de 12.267 habitantes, aproximadamente esta cifra supone una pérdida poblacional de un 60\% desde 1950.

Es más, desde 2003, año de la declaración de "Monfragüe" como $R B M$, la población absoluta se ha reducido en un 4,3\%, poniendo de manifiesto que, aún registrando un descenso relativo menor en el número total de habitantes que en la segunda mitad del siglo XX, la debilidad demográfica de este territorio se asocia, por un lado y como se analizará posteriormente, a la quiebra del crecimiento natural y al mantenimiento de unas altas tasas de mortalidad debidas al profundo envejecimiento demográfico y, por otro, a una evidente incapacidad de este territorio, pese a tener el motor ambiental de una $R B$ y de un Parque Nacional, para frenar el proceso de declive demográfico (Figura 2).

\section{Figura 2}

EVOLUCIÓN DE LA POBLACIÓN ABSOLUTA EN LA RBM

(2003-2020)

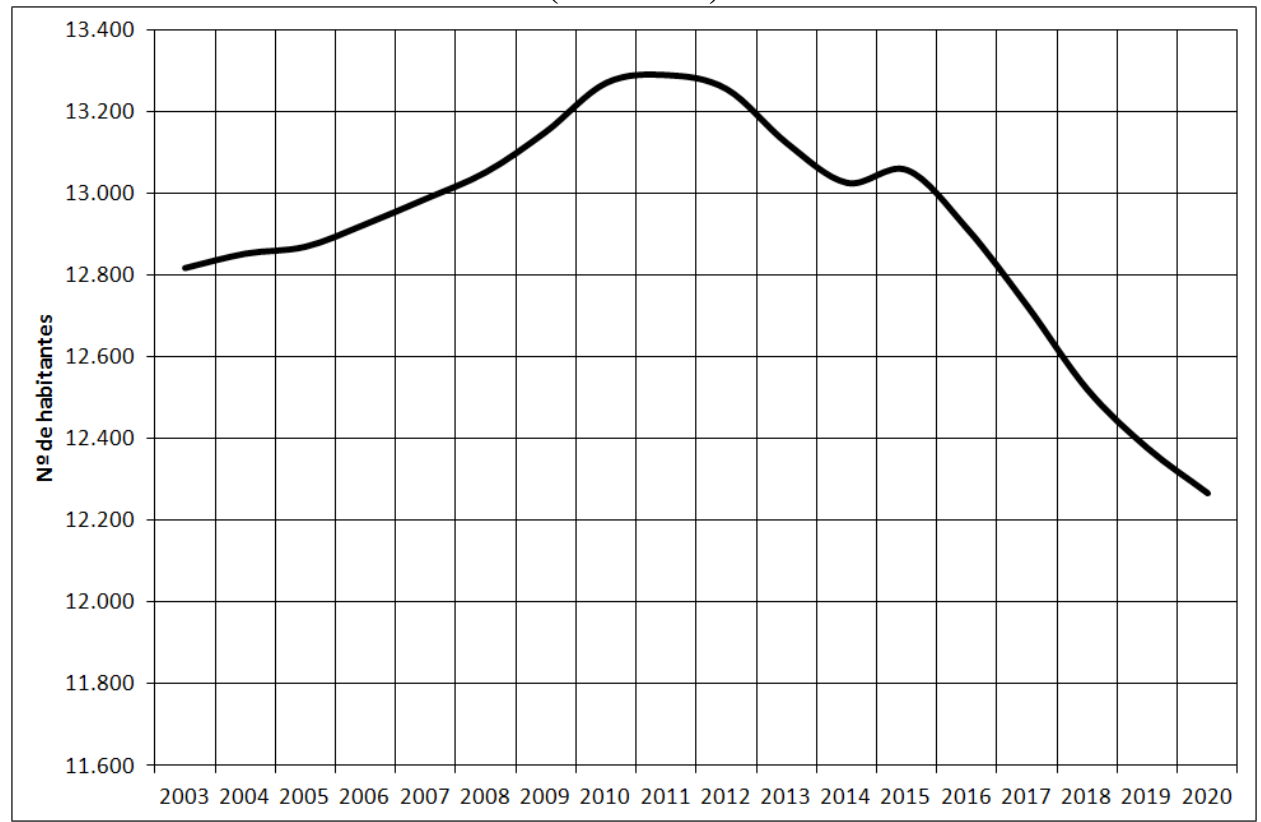

Fuente: Elaboración propia, a partir de datos del INE. 


\subsection{Dinámica natural}

Las bajas densidades demográficas debidas, por un lado, a la despoblación y al éxodo rural y, al tiempo, desencadenantes de un comportamiento negativo del crecimiento natural, han sido objeto de estudio en la literatura científica con muchos y variados ejemplos, o bien aplicados de forma general (Serrano Martínez y García Marín, 2013), o bien aplicados en marcos territoriales concretos (Leco et al., 2017; Gil et al., 2020; García Marín, 2011) o bien con aproximaciones puntuales a espacios naturales protegidos (Santos González y Redondo Vega, 2016; Serrano Gil, 2016).

Desde inicios del siglo XX, la $R B M$ arroja un crecimiento natural regresivo. La tendencia de la natalidad es ciertamente preocupante, no en vano el número de nacimientos ha pasado de 512 en el quinquenio 2000-2004 a 353 nacimientos en el último quinquenio. Esta situación negativa y regresiva de la natalidad choca frontalmente con una tasa bruta de mortalidad que se mantiene con valores muy elevados y cercanos al 12,7\%o en el último quinquenio (Cuadro 5).

\section{Cuadro 5}

\section{DINÁMICA DE LAS VARIABLES VEGETATIVAS}

\begin{tabular}{|l|r|r|r|r|r|}
\hline Quinquenios & \multicolumn{1}{|l|}{ Nacimientos } & Defunciones & \multicolumn{1}{l|}{ Saldo } & \multicolumn{1}{|c|}{ TBN (\%o) } & \multicolumn{1}{c|}{ TBM (\%o) } \\
\hline $1995-1999$ & 501 & 852 & -351 & 7,4 & 12,6 \\
\hline $2000-2004$ & 512 & 824 & -312 & 7,9 & 12,7 \\
\hline $2005-2009$ & 491 & 746 & -255 & 7,5 & 11,5 \\
\hline $2010-2014$ & 448 & 785 & -337 & 6,7 & 11,8 \\
\hline $2015-2019$ & 353 & 808 & -455 & 5,5 & 12,7 \\
\hline
\end{tabular}

Fuente: INE y elaboración propia.

Por tanto, el debilitamiento de la dinámica natural de este territorio, unida al reducido tamaño poblacional de la mayoría de los municipios, la tendencia regresiva de los mismos y, como se analizará a continuación, la persistencia de una dinámica espacial que propicia la pérdida de efectivos demográficos desde los núcleos de menor tamaño hacia los de mayor tamaño, generalmente fuera del ámbito territorial de la $R B M$, son dificultades añadidas que en su conjunto frenan cualquier intento de dinamización socioeconómica.

\subsection{Dinámica espacial: de la emigración al retorno}

El alcance del éxodo rural que la $R B M$ sufrió desde mediados del siglo pasado hasta 2015 se cifra en algo más de 18.000 habitantes, una pérdida cifrada en el $42 \%$ de los efectivos demográficos. Sólo entre 1960 y 1970 la población de la Reserva redujo sus efectivos en un 28,4\%, y volvió a perder un 26,2\% entre 1970 y 1981 . No obstante, las características de este éxodo rural son aplicables generalmente a casi todos los espacios rurales extremeños desde mediados del siglo XX hasta la actualidad y, al tiempo, han sido 
objeto de una vasta labor investigadora (Pérez Díaz, 1988; Gurría et al., 2009; Nieto y Gurría, 2005; Barrientos, 2007).

La emigración tradicional de mediados del siglo XX, el denominado éxodo rural, se caracterizó por su carácter familiar y masivo. En cambio, en la actualidad los flujos migratorios son aún más selectivos en su composición y estructura, al tratarse por lo general de personas jóvenes (20 a 35 años) y solteras y, en muchos casos, con alta formación académica.

Curiosamente, y al mismo tiempo, la recesión económica actual ha favorecido una inmigración de retorno que se ha significado en unos flujos positivos en los años de mayor crisis económica. De tal manera que, en años de bonanza económica en el ámbito nacional, se disparó la emigración mientras que, en los años en los que la crisis económica a nivel nacional alcanzó su mayor crudeza, se disparó la inmigración de retorno. Como se detalla en el Cuadro 6, a partir de 2012, cuando empiezan a amainar los efectos de la crisis económica, de nuevo son constantes las pérdidas demográficas por emigración. Es evidente que los reajustes impulsados desde la Política Agrícola Común, las oportunidades laborales para la población activa, especialmente para los jóvenes y las mujeres, entre otros factores, han sido insuficientes reactivos como para frenar este proceso migratorio.

\section{Cuadro 6 \\ EVOLUCIÓN DE LOS SALDOS MIGRATORIOS}

\begin{tabular}{|l|r|}
\hline \multicolumn{1}{|c|}{ Años } & Saldo Migratorio \\
\hline $1991-2001$ & 26 \\
\hline 2002 & -81 \\
\hline 2003 & -64 \\
\hline 2004 & 28 \\
\hline 2005 & 62 \\
\hline 2006 & 133 \\
\hline 2007 & 76 \\
\hline 2008 & 124 \\
\hline 2009 & 156 \\
\hline 2010 & 60 \\
\hline 2011 & 4 \\
\hline 2012 & -83 \\
\hline 2013 & -52 \\
\hline 2014 & 90 \\
\hline 2015 & -82 \\
\hline 2016 & -65 \\
\hline 2017 & -66 \\
\hline 2018 & -36 \\
\hline 2019 & -36 \\
\hline $2002-2019$ & 168 \\
\hline
\end{tabular}

Fuente: INE y elaboración propia. 
Por último, como se indicaba anteriormente, desde 2011 hasta la actualidad, con la excepción hecha de 2014 (y probablemente de 2020 y 2021 debido a la pandemia debida al "covid"), hay una clara tendencia hacia saldos migratorios negativos, sobre todo en los municipios de mayor tamaño poblacional (Malpartida de Plasencia fundamentalmente) que transmiten tales cambios al conjunto de la Reserva de la Biosfera de Monfragüe.

\subsection{Estructura demográfica}

La estructura demográfica de 2020 presenta una pirámide tipo regresiva, caracterizada por una base cada vez más estrecha y estrangulada debido a las bajas tasas de natalidad (la población joven menor de 15 años apenas alcanza el 11\%), una parte media de la pirámide definida por un ensanchamiento cada vez mayor en la población adulta-vieja (el 30,4\% de la población total tiene entre 45y 64 años, valor que en Extremadura apenas alcanza el 24\%) y, por último, una cúspide donde se encuadra la población mayor de 65 años que engloba el 25,1\% de la población total (Figura 3).

Debe significarse, no obstante, la amplia inflexión que muestra la pirámide en los grupos de edad comprendidos entre los 55 y 69 años, situación que está directamente relacionada con la emigración de los años sesenta y setenta del siglo pasado, con independencia de los efectos correctores que en dichas cohortes provoca el flujo de retornados en la actualidad.

Además de esta situación general por edades, la morfología de la estructura demográfica presenta un fuerte desequilibrio entre sexos, tal es así que el 53\% de las personas entre 15 y 64 años son hombres, mientras que un 55\% de las personas mayores de 65 años son mujeres, mostrando claramente una feminización de la vejez.

El desequilibrio estructural de la demografía de este territorio, que alcanza su máxima expresión en el profundo y estructural envejecimiento de la población (el índice de envejecimiento se sitúa en un $227 \%$ frente a una media regional del $130 \%$ ), se debe, sin duda, a algunos de los factores ya comentados anteriormente, como la caída de las tasas de natalidad, el aumento de la esperanza de vida, el carácter selectivo de la emigración, pasada y actual, o una inmigración de retorno preferentemente de personas mayores.

Algunas de las tasas e índices de este territorio ponen de relieve la debilidad estructural del tejido demográfico de la $R B M$ (Cuadro 7). La tasa de dependencia (un $57 \%$ frente a una media regional del 50\%), el índice de envejecimiento (227\% en 2020 por un 196,5\% en 2003), el índice de sobreenvejecimiento (21,7\% en 2020 por un 11,1\% en 2003) o el índice de reemplazo de edad activa total (que pasado de un 130,2\% en 2003 a un 72,9\% en 2020) son variables que, de una u otra manera, lastran las posibilidades de crecimiento y diversificación económica que requiere la zona manteniendo una dinámica demográfica que se asocia a las regiones más remotas y rezagadas (OCDE; 2006). 


\section{Figura 3 \\ ESTRUCTURA DEMOGRÁFICA, 2020}

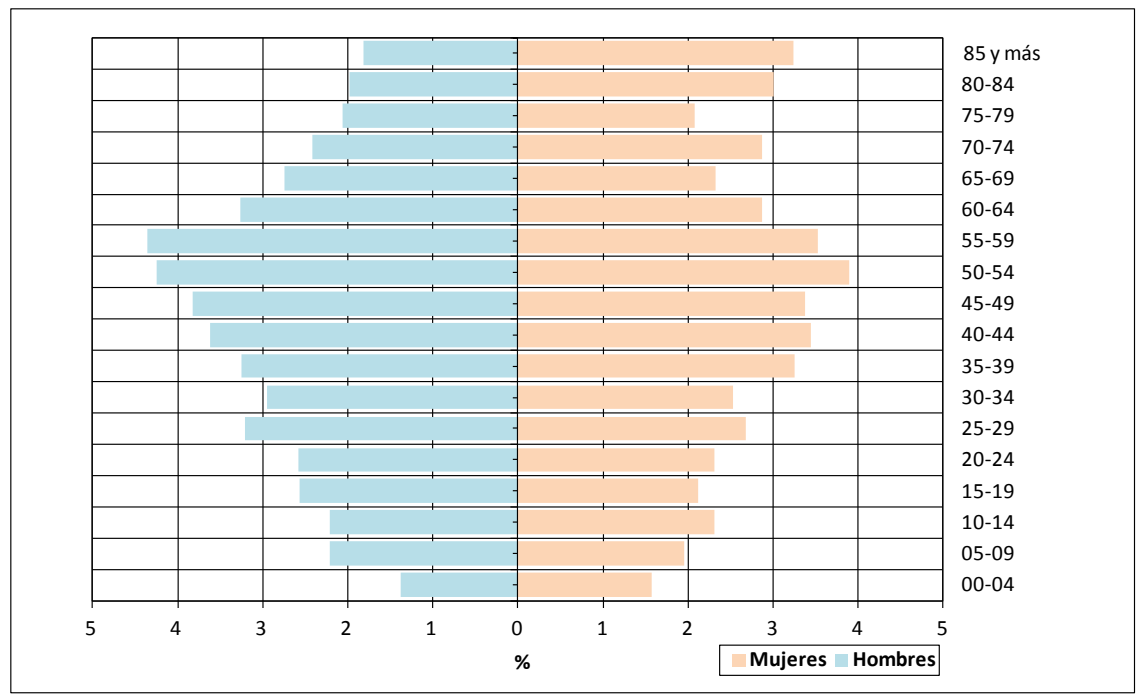

Fuente: INE y elaboración propia.

\section{Cuadro 7}

ANÁLISIS EVOLUTIVO DE INDICADORES DEMOGRÁFICOS, 2003 Y 2020

\begin{tabular}{|c|c|c|}
\hline Indicadores demográficos (\%) & 2003 & 2020 \\
\hline $\begin{array}{l}\text { Población joven } \\
\left(P_{0-14 \text { años }} / P_{\text {Total }}\right) * 100\end{array}$ & 13,0 & 11,1 \\
\hline $\begin{array}{l}\text { Población adulto-joven } \\
\left(P_{15-44 \text { años }} / P_{\text {Total }}\right) * 100\end{array}$ & 41,3 & 33,4 \\
\hline $\begin{array}{l}\text { Población adulto-vieja } \\
\left(P_{45-64 \text { años }} / P_{\text {Total }}\right) * 100\end{array}$ & 20,1 & 30,4 \\
\hline $\begin{array}{l}\text { Población vieja } \\
\left(P_{65 \text { años y más }} / P_{\text {Total }}\right) * 100\end{array}$ & 25,6 & 25,1 \\
\hline $\begin{array}{l}\text { Índice de juventud } \\
\left(P_{0-14 \text { años }} / P_{65 \text { años y más }}\right) * 100\end{array}$ & 50,9 & 44,1 \\
\hline $\begin{array}{l}\text { Índice de envejecimiento } \\
\left(P_{65 \text { años y más }} / P_{0-14 \text { años }}\right) * 100\end{array}$ & 196,5 & 227,0 \\
\hline $\begin{array}{l}\text { Índice de sobreenvejecimiento } \\
\left(P_{85 \text { años y más }} / P_{65} \text { años y más }\right) * 100\end{array}$ & 11,1 & 21,7 \\
\hline $\begin{array}{l}\text { Tasa de dependencia } \\
\left(P_{0-14 \text { años }}+P_{65 \text { años y máss }}\right) / P_{15-64 \text { años }} * 100\end{array}$ & 62,8 & 56,8 \\
\hline $\begin{array}{l}\text { Índice de reemplazo de edad activa total } \\
\left(P_{16-19 \text { años }} / P_{60-64 \text { años }}\right) * 100\end{array}$ & 130,2 & 72,9 \\
\hline
\end{tabular}

Fuente: Elaboración propia 


\subsection{Sectores económicos, paro y renta disponible}

A la hora de realizar un análisis sobre los sectores económicos en este territorio hemos de tener en cuenta, en primer lugar, la existencia de catorce municipios con distinto tamaño poblacional, ese matiz va a introducir diferencias muy marcadas entre ellos. Esto es debido a la mayor tendencia, tanto del número de trabajadores como de las propias empresas, a instalarse en aquellos núcleos que cuentan con mayor dinamismo demográfico. Un claro ejemplo de ello es el municipio de Malpartida de Plasencia que, además de concentrar el 37,5\% de la población total de la $R B M$, aglutina el $40 \%$ del total de los afiliados a la Seguridad Social (Cuadro 8).

\section{Cuadro 8}

AFILIADOS A LA SEGURIDAD SOCIAL POR SECTORES DE ACTIVIDAD, 2020

\begin{tabular}{|c|c|c|c|c|c|c|c|c|c|c|c|c|}
\hline \multirow{2}{*}{ Municipios } & \multicolumn{2}{|c|}{ Agricultura } & \multicolumn{2}{|c|}{ Industria } & \multicolumn{2}{|c|}{ Construcción } & \multicolumn{2}{|c|}{ Servicios } & \multicolumn{2}{|c|}{ Otros } & \multicolumn{2}{|c|}{ Total } \\
\hline & $\mathbf{N}^{\mathbf{o}}$ & $\%$ & $\mathbf{N}^{\mathbf{o}}$ & $\%$ & $\mathbf{N}^{\mathbf{0}}$ & $\%$ & $\mathbf{N}^{\mathbf{o}}$ & $\%$ & $\mathbf{N}^{\mathbf{o}}$ & $\%$ & $\mathbf{N}^{\mathbf{o}}$ & $\%$ \\
\hline Casas de Millán & 33 & 24,3 & 11 & 8,1 & 12 & 8,8 & 78 & 57,4 & 2 & 1,5 & 136 & 100,0 \\
\hline Casas de Miravete & 5 & 16,1 & 0 & 0,0 & 1 & 3,2 & 25 & 80,6 & 0 & 0,0 & 31 & 100,0 \\
\hline Casatejada & 135 & 28,9 & 57 & 12,2 & 35 & 7,5 & 238 & 51,0 & 2 & 0,4 & 467 & 100,0 \\
\hline Deleitosa & 46 & 18,5 & 32 & 12,9 & 32 & 12,9 & 138 & 55,6 & 0 & 0,0 & 248 & 100,0 \\
\hline Higuera & 5 & 25,0 & 1 & 5,0 & 2 & 10,0 & 12 & 60,0 & 0 & 0,0 & 20 & 100,0 \\
\hline Jaraicejo & 36 & 25,5 & 8 & 5,7 & 12 & 8,5 & 83 & 58,9 & 2 & 1,4 & 141 & 100,0 \\
\hline $\begin{array}{l}\text { Malpartida de } \\
\text { Plasencia }\end{array}$ & 142 & 8,7 & 330 & 20,3 & 192 & 11,8 & 955 & 58,8 & 4 & 0,2 & 1.623 & 100,0 \\
\hline Mirabel & 31 & 14,6 & 48 & 22,5 & 16 & 7,5 & 114 & 53,5 & 4 & 1,9 & 213 & 100,0 \\
\hline Romangordo & 3 & 6,8 & 6 & 13,6 & 3 & 6,8 & 32 & 72,7 & 0 & 0,0 & 44 & 100,0 \\
\hline Saucedilla & 61 & 23,7 & 50 & 19,5 & 17 & 6,6 & 129 & 50,2 & 0 & 0,0 & 257 & 100,0 \\
\hline Serradilla & 157 & 31,5 & 28 & 5,6 & 46 & 9,2 & 266 & 53,3 & 2 & 0,4 & 499 & 100,0 \\
\hline Serrejón & 45 & 37,5 & 4 & 3,3 & 5 & 4,2 & 64 & 53,3 & 2 & 1,7 & 120 & 100,0 \\
\hline Toril & 20 & 55,6 & 1 & 2,8 & 0 & 0,0 & 15 & 41,7 & 0 & 0,0 & 36 & 100,0 \\
\hline Torrejón el Rubio & 64 & 33,7 & 11 & 5,8 & 19 & 10,0 & 95 & 50,0 & 1 & 0,5 & 190 & 100,0 \\
\hline Reserva Biosfera & 783 & 19,5 & 587 & 14,6 & 392 & 9,7 & 2.244 & 55,8 & 19 & 0,5 & 4.025 & 100,0 \\
\hline
\end{tabular}

Fuente: INE y elaboración propia.

Aunque ya lejos del $30,2 \%$ de afiliados al sector agrario que presentaba la $R B M$ en 2003 , todavía hoy manifiesta una excesiva dependencia del sector agrario que aglutina el $19,5 \%$ de los afiliados, alcanzando porcentajes elevadísimos en municipios como Serrejón (37,5\%), Torrejón el Rubio (33,7\%) o Serradilla (31,5\%), caso aparte supone el municipio de Toril que con un 55,6\% muestra una "sobredependencia" de la actividad agraria (Gurría et al., 2011). 
Por otro lado, el sector industrial tiene un papel más relevante si lo comparamos porcentualmente con la media extremeña (un $14,6 \%$ en la $R B M$ frente a un $8,0 \%$ de afiliados en Extremadura).

Una situación parecida se repite en el sector de la construcción que en este caso engloba el 9,7\% de los afiliados frente a un 6,4\% de la media extremeña. Por último, el sector servicios acapara el 55,8\% de los afiliados a la Seguridad Social de los catorce términos municipales que conforman la $R B M$. Este sector va tomando peso poco a poco debido sobre todo a la mano de obra que se emplea en la hostelería, restauración,...; en definitiva sectores en auge gracias al turismo rural pero que, sin embargo, todavía hoy se encuentra 11 puntos por debajo de la media extremeña.

En todo caso, hay que destacar que sólo el municipio de Malpartida de Plasencia aglutina el $18,1 \%$ de los afiliados a la agricultura; el 56,2\% de la industria; el $49 \%$ de la construcción y el $42,6 \%$ de los afiliados a los servicios en el conjunto de la $R B M$. Ello, sin duda, pone de relieve la estrecha relación entre el tamaño de la población y el dinamismo económico (la correlación lineal entre el número de afiliados y la población total para el conjunto de municipios es de $\mathrm{r}=0,997)$.

Igualmente, cabe reseñar todavía la enorme distancia entre hombres y mujeres en la afiliación a la Seguridad Social, existiendo a fecha de diciembre de 2020 un 55,5\% de hombres frente a un 44,5\% de mujeres, más de diez puntos de diferencia en la brecha laboral de género. A ello hay que añadir las especiales dificultades de los jóvenes para su incorporación al mercado laboral (sólo un 13\% de los afiliados a la Seguridad Social en 2020 tenía menos de 30 años).

Por otro lado, los datos de la situación del número de empresas con trabajadores en alta en la Seguridad Social por sectores de actividad en 2020 refieren también una fuerte dependencia de las empresas relacionadas con el sector agrario (39,6\% sobre el total), por encima incluso de las empresas del sector servicios $(34,7 \%)$. Tanto las empresas del sector industrial $(12,8 \%)$ como de la construcción $(13,3 \%)$ muestran las mismas debilidades que estas mismas empresas en el conjunto regional, convirtiéndose ello en una debilidad estructural, sobre todo la referente al tejido industrial (Cuadro 9).

\section{Cuadro 9}

EMPRESAS CON TRABAJADORES EN ALTA EN LA SEGURIDAD SOCIAL POR SECTORES DE ACTIVIDAD, 2020

\begin{tabular}{|c|c|c|c|c|c|c|c|c|c|c|}
\hline \multirow[t]{2}{*}{ Municipios } & \multicolumn{2}{|c|}{ Agricultura } & \multicolumn{2}{|c|}{ Industria } & \multicolumn{2}{|c|}{ Construcción } & \multicolumn{2}{|c|}{ Servicios } & \multicolumn{2}{|c|}{ Total } \\
\hline & $\mathbf{N}^{\circ}$ & $\%$ & $\mathbf{N}^{\circ}$ & $\%$ & $\mathbf{N}^{\mathbf{o}}$ & $\%$ & $\mathrm{~N}^{\mathbf{0}}$ & $\%$ & $\mathrm{~N}^{\circ}$ & $\%$ \\
\hline Casas de Millán & 10 & 76,9 & 0 & 0,0 & 1 & 7,7 & 2 & 15,4 & 13 & 100,0 \\
\hline Casas de Miravete & 3 & 75,0 & 0 & 0,0 & 0 & 0,0 & 1 & 25,0 & 4 & 100,0 \\
\hline Casatejada & 20 & 50,0 & 7 & 17,5 & 2 & 5,0 & 11 & 27,5 & 40 & 100,0 \\
\hline Deleitosa & 7 & 25,9 & 5 & 18,5 & 3 & 11,1 & 12 & 44,4 & 27 & 100,0 \\
\hline Higuera & 0 & 0,0 & 0 & 0,0 & 1 & 100,0 & 0 & 0,0 & 1 & 100,0 \\
\hline
\end{tabular}




\begin{tabular}{|c|c|c|c|c|c|c|c|c|c|c|}
\hline \multirow[t]{2}{*}{ Municipios } & \multicolumn{2}{|c|}{ Agricultura } & \multicolumn{2}{|c|}{ Industria } & \multicolumn{2}{|c|}{ Construcción } & \multicolumn{2}{|c|}{ Servicios } & \multicolumn{2}{|c|}{ Total } \\
\hline & $\mathbf{N}^{\mathbf{0}}$ & $\%$ & $\mathbf{N}^{\circ}$ & $\%$ & $\mathbf{N}^{\mathbf{o}}$ & $\%$ & $\mathbf{N}^{\mathbf{0}}$ & $\%$ & $\mathbf{N}^{\circ}$ & $\%$ \\
\hline Jaraicejo & 9 & 40,9 & 1 & 4,5 & 1 & 4,5 & 11 & 50,0 & 22 & 100,0 \\
\hline $\begin{array}{l}\text { Malpartida de } \\
\text { Plasencia }\end{array}$ & 40 & 25,6 & 22 & 14,1 & 30 & 19,2 & 64 & 41,0 & 156 & 100,0 \\
\hline Mirabel & 1 & 10,0 & 4 & 40,0 & 2 & 20,0 & 3 & 30,0 & 10 & 100,0 \\
\hline Romangordo & 2 & 25,0 & 1 & 12,5 & 3 & 37,5 & 2 & 25,0 & 8 & 100,0 \\
\hline Saucedilla & 12 & 46,2 & 3 & 11,5 & 3 & 11,5 & 8 & 30,8 & 26 & 100,0 \\
\hline Serradilla & 14 & 38,9 & 4 & 11,1 & 6 & 16,7 & 12 & 33,3 & 36 & 100,0 \\
\hline Serrejón & 11 & 64,7 & 1 & 5,9 & 1 & 5,9 & 4 & 23,5 & 17 & 100,0 \\
\hline Toril & 13 & 72,2 & 1 & 5,6 & 0 & 0,0 & 4 & 22,2 & 18 & 100,0 \\
\hline Torrejón el Rubio & 21 & 61,8 & 2 & 5,9 & 2 & 5,9 & 9 & 26,5 & 34 & 100,0 \\
\hline Reserva Biosfera & 163 & 39,6 & 51 & 12,4 & 55 & 13,3 & 143 & 34,7 & 412 & 100,0 \\
\hline
\end{tabular}

Fuente: INE y elaboración propia.

Como sucedía en el caso de los trabajadores, Malpartida de Plasencia acapara el 24,7\% de las empresas agrarias del conjunto territorial de la $R B M$; el $46 \%$ de las relacionadas con la industria; el 50,8\% de las empresas del sector de la construcción y el $42,8 \%$ de las empresas del sector servicios, en conjunto acumula el $37,2 \%$ de todas las empresas de la Reserva de la Biosfera de Monfragüe. Por lo tanto, insistimos en que el tamaño poblacional de un municipio influye directamente en el dinamismo económico, además el tamaño poblacional es un factor decisivo de localización industrial que, en este caso, se une a una buena localización geográfica junto a la Autovía EXA1 que conecta Plasencia con Navalmoral de la Mata.

Otra variable que habla de la crisis territorial del conjunto de este territorio es el paro. La tasa de paro también se mantiene en valores relativamente altos desde 2006 (Cuadro 10), no es menos cierto que el paro es preocupante en casi todos los territorios de bajas densidades demográficas. Es más, aunque entre 2010-2015 se produjo una leve recuperación de los efectivos demográficos en la $R B M$ (ver Cuadro 5), debido a saldos migratorios positivos de los años anteriores, esta situación no sólo no sirvió para alentar la economía y la demografía local, sino que además tuvo un efecto contrario ya que dicha tasa alcanzó valores medios del 27\%. En cualquier caso, el número total de parados se mantiene en cifras muy altas desde 2007 (1.048 parados), frente a los 1.067 parados registrados en 2020, (Fuente: Instituto de Estadística de Extremadura), siendo especialmente preocupante el paro entre mujeres (en 2020 seis de cada diez personas en paro eran mujeres en la $R B M)$. 


\section{Cuadro 10}

\section{RENTA FAMILIAR DISPONIBLE Y TASA DE PARO, 2020}

\begin{tabular}{|l|r|r|r|r|}
\hline \multirow{2}{*}{ Territorio } & \multirow{2}{*}{$\begin{array}{c}\text { Renta Familar } \\
\text { Disponible } \\
\text { (euro/habitante) }\end{array}$} & \multicolumn{2}{|c|}{ Hombres } & \multicolumn{2}{|c|}{ Mujeres } & \multicolumn{1}{|c|}{ Total } \\
\cline { 4 - 5 } & 10.880 & 11,3 & 18,8 & 14,4 \\
\hline$R B M$ & 11.652 & 9,8 & 15,4 & 12,5 \\
\hline Provincia de Cáceres & 10.894 & 9,6 & 18,1 & 13,8 \\
\hline Provincia de Badajoz & 11.175 & 9,6 & 17,1 & 13,3 \\
\hline Extremadura & 14.781 & 7,9 & 11,8 & 9,9 \\
\hline España & & & & \\
\hline
\end{tabular}

Fuente: Atlas Socioeconómico de Extremadura. Instituto de Estadística de Extremadura. (https://ciudadano. gobex.es/web/ieex/ieex)

Por último, se ha analizado otro indicador socioeconómico que entendemos de gran importancia para valorar los cambios en la economía local, se trata de la "renta media disponible" (Cuadro 10). Este indicador mide el "nivel de renta de que disponen las economías domésticas para gastar y ahorrar, o bien como la suma de todos los ingresos efectivamente percibidos por las economías domésticas durante un período, por lo que puede considerarse como el total de ingresos procedentes del trabajo, más las rentas del capital, prestaciones sociales y transferencias, menos los impuestos indirectos y las cuotas" (Atlas Socioeconómico de Extremadura, 2019).

En este sentido, desde 2007, año de la declaración de "Monfragüe" como Parque Nacional, la renta media disponible ha pasado de 11.044 euros a 10.880 euros en 2019, se observa, por tanto, una pérdida de renta $(-1,5 \%)$ que refiere, además de una crisis demográfica estructural, un estancamiento y recesión económicas muy significativas dado el aumento del nivel de vida en las dos últimas décadas.

Una recesión económica que es generalizada a casi todos los espacios geográficos (entre 2007 y 2019 Extremadura sufre una pérdida de renta media disponible del 1,6\% y España cifra esa pérdida en el 1,8\%) siendo especialmente sangrante en territorios de bajas densidades demográficas como Monfragüe.

\section{EL TURISMO FRENTE AL RETO DE LA DIVERSIFICACIÓN ECONÓMICA}

La promoción del turismo rural es una de las propuestas más atractivas que se pueden llevar a cabo para la valorización de los recursos naturales y culturales, así como para la creación de empleo (Aparicio, 2004; Castro, 2007; Sánchez y Sánchez, 2018). El contexto territorial que ofrece la $R B M$ posee una serie de oportunidades para el turismo rural excepcionales, sin embargo esas oportunidades pasan primero por la puesta en valor de sus recursos patrimoniales desde una perspectiva global y transversal.

El patrimonio debe ser una de las estrategias principales de desarrollo en territorios de bajas densidades demográficas (Silva Pérez y Fernández Salinas, 2017; Feria, 2013; Mata, 2008), en tanto que adquiere una significado especial cuando se considera como uno de los recursos principales de los territorios susceptibles de generar riqueza (Caravaca Barroso 
et. al., 1997). Por ello, el patrimonio debe ser considerado, primero, como elemento de identidad territorial, segundo, como pilar básico con capacidad para generar empleo (catalogación, rehabilitación, conservación, etc.) (COTEC, 2010) y, tercero, como base para poner en valor, a través del turismo, muchos de los recursos territoriales de la $R B M$.

Desde esa perspectiva, la promoción de la actividad turística ha sido de hecho una de las estrategias de desarrollo rural que han seguido los Grupos de Acción Local dentro de los programas Leader, ya que no sólo deberían ayudar a diversificar sus debilitadas economías sino también ser un instrumento para llevar a cabo estrategias de desarrollo local participativo que contribuyan a conservar y recuperar el patrimonio aunque, también es cierto, que "no todos los territorios rurales han conseguido por igual sus propósitos", destacando en España aquellos espacios que previamente tenían una cierta consolidación del turismo como "Pirineos, Sierras de Madrid, Gredos, Covadonga, la montaña cántabra, Cazorla o Grazalema" (Jurado y Pazos-García, 2016: 268).

Hay que insistir, en este sentido, que hasta el actual Programa Operativo 2014-2020 ha habido una parcial y manifiesta desunión de los municipios del Área de Influencia Socioeconómica del PN y RBM. Así en el Programa FEADER (2007-2013) los municipios de dicha área de influencia estaban desagregados en cuatro Grupos de Acción Local: "ADEME" (Asociación para el Desarrollo de Monfragüe y su Entorno), que incluía los municipios de Casas de Millán, Malpartida de Plasencia, Mirabel, Serradilla, Torrejón el Rubio, Cañaveral y Pedroso de Acim (éstos dos últimos curiosamente fuera del Área de Influencia Socioeconómica); "ADICOMT" (Asociación para el Desarrollo Integral de la Comarca Miajadas-Trujillo) que incluía al municipio de Jaraicejo; "APRODERVI” (Asociación para la Promoción y el Desarrollo Rural de las Villuercas, Ibores y La Jara) que contenía a Deleitosa; y "ARJABOR” (Asociación para el Desarrollo de la Comarca del Campo Arañuelo), que incluía los municipios de Casas de Miravete, Casatejada, Higuera, Romangordo, Saucedilla, Serrejón y Toril. Es más, incluso en el actual Programa Operativo 2014-2020 esos problemas estructurales persisten (los municipios de Cañaveral y Pedroso de Acim, sin pertenecer al Área de Influencia Socioeconómica, siguen estando presentes en "ADEME"; Casatejada y Deleitosa, aún perteneciendo ambos a dicha área de influencia, siguen permaneciendo a "ARJABOR" y a "APRODERVI" respectivamente).

En todo caso, en el Grupo de Acción Local “ADEME” se observa que, en el "Programa Enfoque Leader 2007-2013" (FEADER), la Submedida 3.1.3 de "Fomento de actividades turísticas" acaparó el 16,2\% del total de las inversiones acometidas en ese período ${ }^{1}$.

En cambio, en el actual Programa Operativo 2014-2020, todavía no finalizado, el Grupo de Acción Local "Ademe" ha concedido a proyectos relacionados con el desarrollo de empresas y/o actividades relacionadas con el turismo un 40,5\% de las ayudas totales (Fuente: ADEME), evidenciado todavía una proyección importante de futuro pero, al mismo tiempo, poniendo de manifiesto que "aquellas comarcas con mejores resultados de eficacia y eficiencia en turismo rural presentan a la vez los peores indicadores económicos

1 El fomento del turismo en el Grupo de Acción Local de "Ademe" (unidos los Programas Leader II/Proder I 1994-1999; Leader +/Proder II 2000-2006 y FEADER 2007-2013) supuso una inversión media del 42,5\%, frente a una media extremeña del $23,7 \%$, si bien hay que tener en cuenta que en estos períodos sólo formaban parte del Grupo de Acción Local siete municipios y, de entre ellos, sólo cinco pertenecientes al Área de Influencia Socioeconómica (Casas de Millán, Malpartida de Plasencia, Mirabel, Serradilla y Torrejón el Rubio). 
y demográficos" (Nieto y Cárdenas, 2017: 409), especialmente en aquellos más regresivos y más envejecidos (Nieto y Cárdenas, 2015). Aunque, por otro lado, también cabría la posibilidad de preguntarse cuál habría sido el panorama demográfico y económico de este territorio sin la promoción del turismo rural.

En este sentido, la $R B M$ tiene todavía una oferta alojativa relativamente escasa y poco diversificada, no obstante a medio plazo parece suficiente para alojar la demanda actual, como se verá más adelante.

En todo caso, según la información facilitada por la Dirección General de Sostenibilidad de la Consejería para la Transición Ecológica y Sostenibilidad de la Junta de Extremadura, referida al dato real del número de personas que registran su visita en el Centro de Visitantes del Parque Nacional de Monfragüe, el número de visitantes ascendió en 2019 a 69.121 (según estimaciones de la Red de Parques Nacionales la cifra de visitas en 2017 fue de 288.589) (Fuente: https://www.miteco.gob.es/es/red-parques-nacionales/ la-red/gestion/visitasppnn_tcm30-67283.pdf) (Figura 4).

\section{Figura 4 \\ FLUJO DE VISITANTES AL CENTRO DE INFORMACIÓN DE LA RBM Y PNM, 2019}

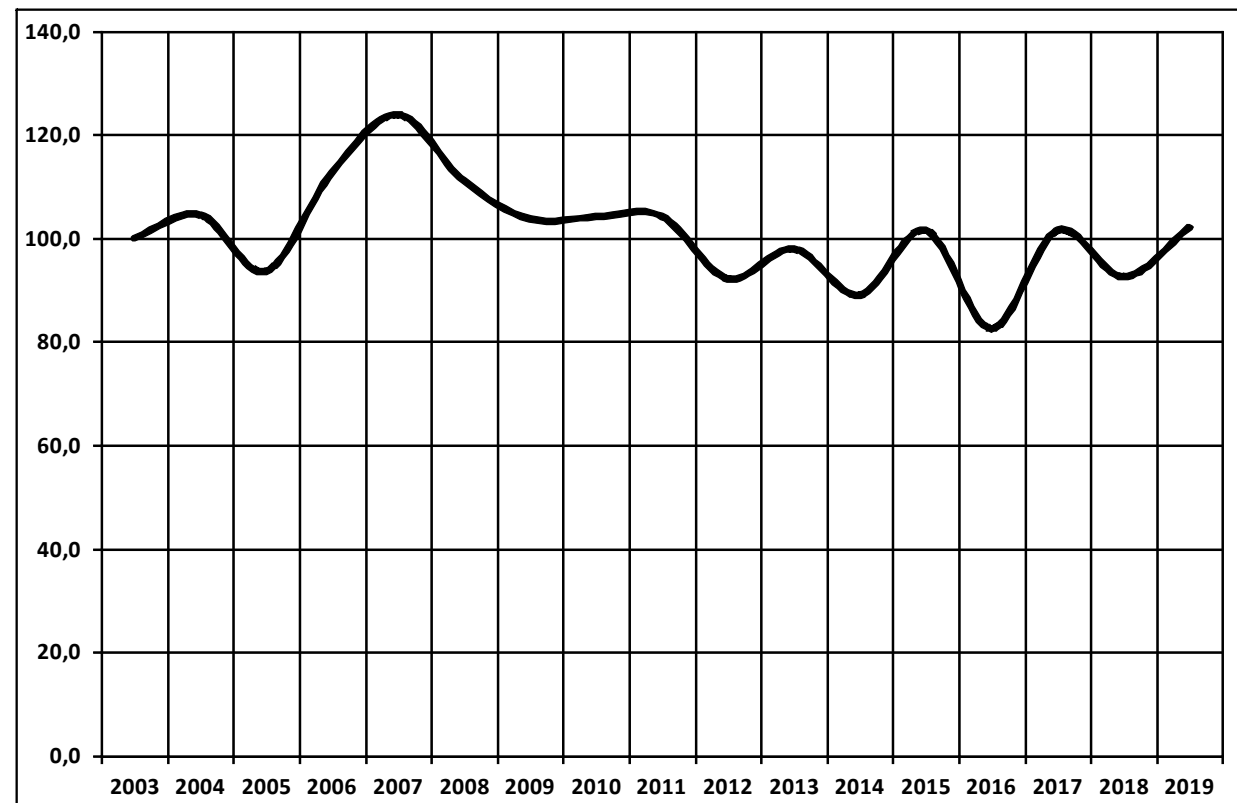

Año inicial (2003): 67.714 visitantes $=100$

Fuente: Dirección General de Sostenibilidad. Junta de Extremadura.

Los atractivos turísticos de este espacio protegido explican que casi una tercera parte de todos los visitantes de espacios protegidos en Extremadura visiten Monfragüe. Entre 
2003 y 2019 pasaron por el Centro de Visitantes del Parque Nacional un total de 1.162.550 personas, concretamente el 31,1\% del total que recibió el conjunto de la Red Extremeña de Espacios Protegidos. La evolución anual muestra valores curiosamente más altos en los años 2006, 2007 (año de la declaración de Parque Nacional) y 2008. En todo caso, ofrece una media anual de visitantes entre 2003 y 2019 que asciende a 68.385 personas.

Por otro lado, la estacionalidad mensual de las visitas es todavía muy irregular y presenta graves problemas de concentración de la demanda en determinadas épocas del año (Cuadro 11). De este modo, se observa que los meses de marzo, abril y mayo (coincidentes en fechas con la "Feria Ornitológica de Monfragüe", la "Semana Santa" y el "Puente de Mayo") acaparan el 48,64\% de las mismas. Sólo el mes de octubre, fuera de estas fechas, y coincidente con la otoñada registra una media de visitas que superó el 10\% entre 2003 y 2019. El resto de meses, fundamentalmente los invernales (desde noviembre a febrero) y los meses más cálidos (junio, julio y agosto) no ofrecen al visitante, al menos hasta la actualidad, un atractivo como para incrementar las visitas y, en todo caso, para poder desestacionalizar la concentración de la demanda actual que, en determinadas épocas del año, clama por una planificación y gestión ordenada del uso público (Leco, Pérez y Mateos, 2013).

\section{Cuadro 11}

\section{PORCENTAJE MEDIO DE VISITAS MENSUALES REGISTRADAS EN EL CENTRO DE INFORMACIÓN DE LA RBM Y PNM, 2003-2019}

\begin{tabular}{|c|c|c|c|c|c|c|c|c|c|c|c|}
\hline Ene & Feb & Mar & Abr & May & Jun & Jul & Ago & Sep & Oct & Nov & Dic \\
\hline 2,18 & 4,32 & 12,40 & 21,54 & 14,69 & 6,22 & 4,02 & 7,66 & 6,80 & 10,38 & 5,34 & 4,43 \\
\hline
\end{tabular}

Fuente: Dirección General de Sostenibilidad. Junta de Extremadura.

En cualquier caso, las cifras globales refieren una importante capacidad de atracción turística de este territorio, sin embargo esa capacidad no encuentra de hecho el reflejo que cabría esperar en la oferta y demanda alojativa.

En el Cuadro 12 se muestran las diferentes categorías y clases de alojamientos recogidos en la Ley 6/2018, de 12 de julio, de modificación de la Ley 2/2011, de 31 de enero, de desarrollo y modernización del turismo de Extremadura (DOE núm. 137, de 16 de julio de 2018).

Estas categorías están compuestas por alojamientos hoteleros (hoteles, hoteles-apartamentos, hostales y pensiones), alojamientos extrahoteleros (apartamentos turísticos, albergues y campamentos de turismo) y alojamientos de turismo rural (hoteles y casas rurales) (Rengifo y Sánchez, 2019). 


\section{Cuadro 12 \\ NÚMERO, CLASE DE ALOJAMIENTOS Y PLAZAS OFERTADAS, 2006-2019}

\begin{tabular}{|l|r|r|r|r|}
\hline \multirow{2}{*}{ Clases de alojamientos } & \multicolumn{3}{|c|}{2006} & \multicolumn{2}{c|}{2019} \\
\cline { 2 - 6 } & \multicolumn{1}{|c|}{$\mathbf{N}^{\mathbf{0}}$} & \multicolumn{1}{c|}{ Plazas } & \multicolumn{1}{c|}{$\mathbf{N}^{\mathbf{0}}$} & \multicolumn{1}{c|}{ Plazas } \\
\hline Hoteleros & 9 & 409 & 8 & 377 \\
\hline Extrahoteleros & 2 & 410 & 11 & 460 \\
\hline Rurales & 21 & 281 & 38 & 416 \\
\hline
\end{tabular}

Fuente: Junta de Extremadura y elaboración propia.

Dentro de la tipología de alojamientos hoteleros se observa un ligero retroceso en el número absoluto de plazas (un $8 \%$ de plazas menos desde 2006). Se ha de resaltar que sólo un hotel de tres estrellas en Malpartida de Plasencia y otro de cuatro estrellas en Torrejón el Rubio ("Hospedería de Monfragüe") acaparan el 64\% de la oferta alojativa hotelera de la Reserva de la Biosfera de Monfragüe (Cuadro 13)

Por otro lado, también desde 2006, dentro de los alojamientos extrahoteleros el número de los apartamentos turísticos pasó de 1 a 10, aumentando igualmente las plazas, si bien en esta tipología de alojamientos el $88 \%$ de las plazas están ofertadas por el "Camping Monfragüe", localizado también en el término municipal de Malpartida de Plasencia.

Respecto a los alojamientos rurales hay que señalar que ha habido un aumento espectacular de 21 a 38 casas rurales entre 2006 y 2019, y por tanto un incremento asociado en el número de plazas ofertadas en un $48 \%$. Hay que resaltar que los municipios de Malpartida de Plasencia, Torrejón el Rubio y Serradilla concentran el 73,7\% de los alojamientos actuales y el $72,3 \%$ de las plazas ofertadas en la $R B M$. No en vano, sólo en el "Programa Enfoque Leader 2007-2013" estos tres municipios sumaron el 60\% de la inversión total (subvención pública más inversión privada) de la Submedida 3.1.3 de "Fomento de actividades turísticas".

No debe pasar por alto que algunos de los términos municipales, quizás por su escasa aportación de superficie protegida a la RBM o por su situación más periférica, no tienen oferta alojativa alguna o relevante (Casas de Millán, Deleitosa, Higuera, Mirabel o Saucedilla) limitando, por tanto, su capacidad de atracción turística.

\section{Cuadro 13}

NÚMERO, TIPOLOGÍA DE ALOJAMIENTOS Y PLAZAS OFERTADAS, 2019

\begin{tabular}{|c|l|r|r|}
\hline Clase de alojamientos & \multicolumn{1}{|c|}{ Tipos de alojamientos } & \multicolumn{1}{c|}{$\mathbf{N}^{\mathbf{0}}$} & \multicolumn{1}{c|}{ Plazas } \\
\hline \multirow{4}{*}{$\begin{array}{c}\text { Alojamientos } \\
\text { hoteleros }\end{array}$} & Hotel 4**** & 1 & 120 \\
\cline { 2 - 4 } & Hotel 3*** & 1 & 122 \\
\cline { 2 - 4 } & Hotel 2** & 0 & 0 \\
\cline { 2 - 4 } & Hotel 1* & 1 & 24 \\
\cline { 2 - 4 } & Hostal 2** & 3 & 23 \\
\cline { 2 - 5 } & Hostal 1* & 1 & 70 \\
\cline { 2 - 5 } & Pensión & & 18 \\
\hline
\end{tabular}




\begin{tabular}{|c|c|c|c|}
\hline Clase de alojamientos & $\begin{array}{c}\text { Tipos de alojamientos } \\
\end{array}$ & $\mathbf{N}^{\circ}$ & Plazas \\
\hline \multirow{4}{*}{$\begin{array}{l}\text { Alojamientos } \\
\text { extrahoteleros }\end{array}$} & Apto. Turístico $3^{\mathrm{a}}$ & 2 & 10 \\
\hline & Apto. Turístico $4^{\mathrm{a}}$ & 8 & 45 \\
\hline & Albergue & 0 & 0 \\
\hline & Campings $1^{\mathrm{a}}$ & 1 & 405 \\
\hline \multirow{5}{*}{$\begin{array}{l}\text { Alojamientos } \\
\text { rurales }\end{array}$} & Casa Rural** & 8 & 75 \\
\hline & Casa Rural*** & 17 & 168 \\
\hline & Casa Rural $* * * *$ & 11 & 119 \\
\hline & Casa Rural $* * * * *$ & 1 & 14 \\
\hline & Hotel Rural** & 1 & 40 \\
\hline Otros & Empresas de actividades & 14 & \\
\hline \multicolumn{2}{|l|}{ Totales } & 56 & 1.253 \\
\hline
\end{tabular}

Fuente: Junta de Extremadura, 2019.

En otro orden de cosas, se ha de destacar que el volumen de viajeros que llega a la $R B M$ alcanzó en 2018 el 3,8\% del total de Extremadura, que ascendió a 1.866 .168 viajeros (Fuente: Observatorio de Turismo de Extremadura). En este año el número de viajeros registrados en alojamientos en el área de Monfragüe ascendió a 71.041 personas.

A pesar de esa importante cifra, el grado de ocupación media anual fue del 19,5\% en 2018. La ocupación media más alta se presenta en los alojamientos hoteleros (27,5\%), mientras que los alojamientos rurales apenas si alcanzan una ocupación media anual del $13,7 \%$ (Cuadro 15).

\section{Cuadro 15}

GRADO DE OCUPACIÓN TRIMESTRAL POR TIPOS DE ALOJAMIENTO, $2018(\%)$

\begin{tabular}{|l|r|r|r|r|r|}
\hline \multicolumn{1}{|c|}{ Tipo de alojamiento } & \multicolumn{1}{|c|}{ 1er trim. } & \multicolumn{1}{c|}{$\mathbf{2}^{\mathbf{0}}$ trim. } & \multicolumn{1}{c|}{ 3er trim. } & \multicolumn{1}{c|}{$\mathbf{4}^{\mathbf{}}$ trim. } & \multicolumn{1}{c|}{ Media } \\
\hline Hoteles & 24,1 & 31,3 & 28,6 & 26,2 & 27,5 \\
\hline Hostales & 10,4 & 17,1 & 19,5 & 10,0 & 14,4 \\
\hline Pensiones & 4,7 & 21,7 & 16,2 & 6,2 & 12,2 \\
\hline Casas rurales & 3,6 & 15,5 & 23,1 & 12,7 & 13,7 \\
\hline Medias & 13,8 & 25,6 & 22,8 & 15,9 & 19,5 \\
\hline
\end{tabular}

Fuente: Observatorio de Turismo de Extremadura, 2018.

Sin embargo, los enormes atractivos culturales y naturales de este territorio pueden ser la razón por la que la estancia media de los viajeros se eleve a 2 días de media, valor por encima de la media extremeña. Alcanzando valores por encima de los dos días en la primavera (2,23 días) y en el verano (2,07 días). Si bien, el grado de ocupación medio mensual denota todavía una marcada concentración de las visitas en primavera y verano (sobre todo los meses de abril, mayo y agosto, meses por encima de la media anual cifrada en un $19,5 \%$ ). Ahora bien, el grado de ocupación mensual (hotelera y extrahotelera) mues- 
tra claramente que los valores del conjunto regional están, mes a mes, muy por encima de los valores que arroja la $R B M$ (Cuadro 16).

\section{Cuadro 16}

GRADO DE OCUPACIÓN HOTELERA Y EXTRAHOTELERA, EXTREMADURA vs. RB Y PNM, 2018 (\%)

\begin{tabular}{|l|c|c|c|c|c|c|c|c|c|c|c|c|}
\hline & Ene & Feb & Mar & Abr & May & Jun & Jul & Ago & Sep & Oct & Nov & Dic \\
\hline Extremadura & 12,1 & 16,5 & 20,3 & 28,9 & 24,4 & 22,4 & 25,8 & 36,0 & 25,1 & 26,2 & 18,2 & 18,6 \\
\hline$R B M$ & 7,2 & 10,8 & 16,3 & $\mathbf{2 9 , 5}$ & $\mathbf{2 4 , 9}$ & 19,0 & 17,6 & $\mathbf{2 7 , 8}$ & 18,3 & 18,6 & 11,5 & 10,3 \\
\hline
\end{tabular}

Fuente: Observatorio del Turismo de Extremadura, 2018.

No obstante, los indicadores de demanda señalan que un $75,86 \%$ de la misma se refiere a viajeros alojados en establecimientos hoteleros, de los que un $84,87 \%$ son españoles y, de otro lado, un 14,06\% de viajeros prefiere alojarse en el camping (Cuadro 17). Estos aspectos abundan, por un lado, en la escasa internacionalización de las visitas y, por otro lado, en la preferencia de los viajeros por establecimientos hoteleros a pesar de la excelente oferta de alojamientos rurales, aunque concentrados territorialmente como se mencionó anteriormente.

Evidentemente, la contraposición de precios y calidad entre establecimientos hoteleros, por un lado, y el camping existente, por otro, hacen igualmente que la estancia media se eleve a 2,81 días en el segundo de los casos y sólo alcance 1,82 noches en el caso de los establecimientos hoteleros.

Cuadro 17

INDICADORES DE DEMANDA EN LA RBM Y PNM, 2018 (\%)

\begin{tabular}{|l|r|r|r|r|r|}
\hline \multirow{2}{*}{ Tipología } & \multicolumn{3}{|c|}{ Viajeros } & $\begin{array}{c}\mathbf{N}^{\circ} \text { de } \\
\text { pernoctaciones }\end{array}$ & $\begin{array}{c}\text { Estancia } \\
\text { media }\end{array}$ \\
\cline { 2 - 5 } & Españoles & Extranjeros & Totales & & \\
\hline $\begin{array}{l}\text { Establecimientos } \\
\text { hoteleros }\end{array}$ & 45.743 & 8.153 & 53.896 & 98.204 & 1,82 \\
\hline Alojamientos rurales & 5.394 & 506 & 5.900 & 12.816 & 2,17 \\
\hline Apartamentos rurales & 1.108 & 151 & 1.259 & 2.744 & 2,18 \\
\hline Camping & 5.263 & 4.724 & 9.987 & 27.972 & 2,81 \\
\hline Totales & 57.508 & 13.534 & 71.042 & 141.736 & 2,00 \\
\hline
\end{tabular}

Fuente: Observatorio del Turismo de Extremadura, 2018.

\section{CONCLUSIONES}

En conclusión, la Reserva de la Biosfera (2003) y Parque Nacional de Monfragüe (2007) es un territorio que suma un buen número de figuras de protección de la naturaleza (ámbitos internacional, nacional y regional) debido a los valores patrimoniales que 
encierra, siendo especialmente reseñables y señeros los relativos al bosque mediterráneo y a las especies de fauna y flora que lo acompañan.

Desde el punto de vista demográfico, el análisis general de la evolución de la población de los municipios de la $R B M$ revela una situación regresiva y negativa desde 2003 , como así lo muestran los indicadores demográficos que, primero, ponen de relieve la sangría continuada de efectivos demográficos (desde 2003 la población ha sufrido un descenso relativo del 4,3\%); segundo, la quiebra del crecimiento natural de la población que se caracteriza por la alta tasa bruta de mortalidad $(12,7 \%$ ) y la cada vez más baja tasa bruta de natalidad en el último quinquenio (5,5\%o); tercero, por unos saldos migratorios que, igualmente, son negativos en el último quinquenio; cuarto, por la presencia de una estructura demográfica cada vez más envejecida (el índice de envejecimiento ha pasado de un 196,5\% en 2003 a un $227 \%$ en 2020 y, a su vez, el índice de sobreenvejecimiento ha crecido diez puntos porcentuales en ese período, situándose en 2020 en un 21,7\%), entre otros indicadores.

Por tanto, queda demostrado que, desde el punto de vista demográfico, existe una clara desestructuración: la despoblación, provocada por el éxodo rural de los años sesenta y setenta del siglo pasado, acabó originando un profundo envejecimiento demográfico, unas altas tasas de masculinización y una dinámica natural regresiva en los últimos años que, en definitiva, ha provocado una quiebra del tejido social que imposibilitará a corto y medio plazo cualquier modelo de desarrollo sostenible.

A su vez, los indicadores económicos muestran una enorme dependencia agraria (cerca del $20 \%$ de los afiliados a la Seguridad Social pertenecen a este sector); una debilidad estructural de los sectores de la construcción y la industria, a la par que todo el conjunto extremeño; y, un sector servicios, que aunque aglutina el 55,8\% de los afiliados está muy por debajo de la media extremeña y muy lejos de las posibilidades del territorio y las inversiones recibidas en este sentido.

Cabe referirse a otras variables del mercado laboral, como la tasa de paro, que sigue siendo muy elevada en números relativos (la tasa de paro alcanzó un 14,4\% en 2020), poniendo de manifiesto las escasas oportunidades laborales que ofrece este territorio en todos los sectores económicos, especialmente el sector servicios que no alcanza a desarrollar todas sus enormes posibilidades en la creación de empleo.

En este sentido, el sector turístico en este territorio, aún recibiendo un importante número de visitantes al año (un tercio de las visitas anuales que recibe la Red de Espacios Naturales Protegidos de Extremadura se adscriben territorialmente a la Reserva de la Biosfera y Parque Nacional de Monfragüe), viene caracterizado, primero, por una marcada estacionalidad de la demanda (casi el 50\% de las visitas tiene lugar en los meses primaverales); segundo, por presentar igualmente una demanda con una baja aportación de turistas internacionales; tercero, por un grado de ocupación hotelera medio anual que apenas alcanza el 19\%, viéndose reducido a sólo un 13,7\% para la modalidad de alojamientos rurales; y, cuarto, a pesar del aumento de la oferta alojativa, en número de plazas y tipo de alojamientos desde 2006, éste se ha producido básicamente en unos pocos municipios de la $R B M$. Esta concentración limita, en parte, la capacidad de atracción turística que tienen otros municipios dentro de este territorio. 
Por todas estas razones, las expectativas halagüeñas que la Administración depositó en la declaración de Monfragüe, primero como Reserva de la Biosfera en 2003 y, segundo, como Parque Nacional en 2007, no han sido capaz de generar unas sinergias positivas ni en el ámbito demográfico ni en el ámbito socioeconómico, a pesar de las elevadas inversiones que se han realizado, muchas de ellas vinculadas a los fondos europeos para la diversificación económica de los espacios rurales (Programas Leader y Feader) y gestionadas por los Grupos de Acción Local.

Sobre todo en el sector turístico que, en este caso particular, está mostrando una capacidad muy limitada para fijar a la población al territorio (Santos González et al., 2016). Incluso, su asociación con el Parque Nacional de Monfragüe que recibe cerca de 300.000 visitas al año, se muestra claramente insuficiente para tan loables objetivos. Es más, que la $R B M$ comparta territorio con el Parque Nacional puede concluir siendo negativa por cuanto que los intereses de la reserva terminarán supeditados o subordinados a los del parque, constriñendo así su desarrollo.

Cabe recordar que la filosofía de estos espacios protegidos, Reserva de la Biosfera y Parque Nacional de Monfragüe, no se basan únicamente en su consideración como meras figuras de protección, sino "tener capacidad para generar un modelo desarrollo endógeno y sostenible con el medio ambiente a largo plazo y ahí deben encontrar su propia identidad aun no alcanzada" (Santos González et al., 2016: 12). Tanto la figura de Parque Nacional como la figura de Reserva Mundial de la Biosfera son más que suficientes para constituirse en el eje vertebrador de una estrategia de desarrollo local que cohesione el conjunto del Área de Influencia Socioeconómica. Aprovechar las sinergias de su reconocimiento nacional e internacional, la afluencia de turistas, la creación de empresas de servicios y de turismo, de alojamiento, o restauración, etc., con independencia de otras actividades artesanales, industriales y comerciales sólo será posible cuando todos los municipios del $P N$ y $R B M$ se encuentren dentro del mismo Grupo de Acción Local y bajo el paraguas de idénticas estrategias de desarrollo local. El mantenimiento de la situación actual (municipios que no pertenecen al Área de Influencia Socioeconómica están dentro de “ADEME” y otros que, aún perteneciendo, se integran en otros Grupos de Acción Local vecinos) dificulta, no obstante, el aprovechamiento de estas ventajas y una pérdida de sinergias que redundan en perjuicio de las posibilidades que tiene este territorio para vencer algunas de las dificultades extremas que padece, tanto en el plano económico como en el demográfico.

Por ello, una de las pretensiones iniciales de estas figuras de protección de la naturaleza, que deberían haber sido fijar población al territorio, generar empleo, reafirmar la identidad territorial, como verdaderos activos del desarrollo rural/local, hasta la fecha no se han conseguido y, como advierten los indicadores analizados, parece que tampoco se conseguirán a corto y medio plazo.

Declaración responsable: Los autores declaran que no existe ningún conflicto de interés en relación a la publicación de este artículo. Las tareas se han distribuido del modo siguiente. El diseño general del artículo ha sido obra de Felipe Leco Berrocal, así como el apartado de Resultados y Discusión. Las fuentes de información históricas y administrativas, así como las representaciones gráficas y cartográficas han recaído en ambos autores. La redacción del texto, el establecimiento de los objetivos y la metodología, la caracteri- 
zación del área de estudio, así como la correspondiente revisión documental, legislativa y bibliográfica han sido responsabilidad de los dos autores.

\section{BIBLIOGRAFÍA}

ALVARADO CORRALES, E. (2007): «Red Natura 2000 y espacios naturales protegidos en Extremadura. Ámbitos de gestión y participación entre la concertación y el conflicto», en La Geografía en la frontera de los conocimientos. XX Congreso de Geógrafos Españoles, Sevilla, AGE-Universidad de Sevilla.

APARICIO GUERRERO, A.E. (2004): «El turismo rural: una de las alternativas al desarrollo rural en la Serranía de Cuenca», Cuadernos de Turismo, n 13, pp. 73-90.

APARICIO GUERRERO, A.E., GARCÍA MARCHANTE, J.S., MARTÍNEZ NAVARRO, J.M. y VÁZQUEZ VARELA, C. (2012): «Espacios naturales protegidos y capital social: aproximación a dos estudios de caso en Castilla-La Mancha», en Foronda Robles, C. (Coord.) Capital social en espacios naturales protegidos, Ulzama Ediciones, pp. 81-168.

AZQUETA, D. (1997): Valoración económica de la calidad ambiental. Madrid, McGrawHill.

BARRIENTOS ALFAGEME, G. (1979): «Población y territorio», en XXXIII Congreso Luso-Español para el Progreso de la Ciencias. Madrid.

BARRIENTOS ALFAGEME, G. (1983): «Población y territorio en Extremadura», Norba, $\mathrm{n}^{\circ} 4$, pp. 125-135.

BARRIENTOS ALFAGEME, G. (2007): «Las migraciones extremeñas en el último cuarto del siglo XX», Revista de Estudios Extremeños, vol. 63 (3), pp. 1.311-1.330.

BILBAO GONZÁLEZ, R. y DÍEZ CASERO, J. (2010): «Las Reservas de la Biosfera de Castilla y León: una oportunidad frente a la despoblación», en Onaindía Olalde, M. (Ed.) Servicios Ambientales en Reservas de la Biosfera Españolas. Madrid, Organismo Autónomo Parques Nacionales y Red Española de Reservas de la Biosfera, Ministerio de Medio Ambiente y Medio Rural y Marino, pp. 147-167.

BRIONES, G. (1996): Metodología de la investigación cuantitativa en las Ciencias Sociales. Bogotá, Instituto Colombiano para el Fomento de la Educación Superior, 219 pp.

CAMARERO, L. (Coord.) (2009): La población rural de España. De los desequilibrios a la sostenibilidad social. Barcelona, . Fundación "La Caixa", Colección Estudios Sociales, 27.

CANALES MARTÍNEZ, G., SEGRELLES SERRANO, J.A. y VERA-MUÑOZ, M.I. (2012): «El capital social en el entorno de los espacios naturales protegidos de El Hondo y de las Lagunas de La Mata y Torrevieja», en Foronda Robles, C. (Coord.), Capital social en espacios naturales protegidos, Ulzama Ediciones, pp. 171-256.

CANTOS MENGS, F.J. et al. (Coord.) (2010): Guía de Reservas de la Biosfera Españolas. Armonía hombre-naturaleza. Madrid, Organismo Autónomo de Parques Nacionales, 311 pp.

CARAVACA BARROSO, I. et al. (1997): «Patrimonio cultural, territorio y políticas públicas. El caso de Andalucía», Estudios Regionales, n 47, pp. 143-160. 
CASTRO SÁNCHEZ, S. (2007): «Conservación del patrimonio cultural y generación de empleo: posibilidades y riesgos», Cuadernos de Antropología, no 17-18, pp. 115-126.

CEBRIÁN ABELLÁN, F. (Coord.) (2008): Turismo rural y desarrollo local. Cuenca, Universidad de Castilla La Mancha y Universidad de Sevilla, 330 pp.

COLLADO GIRALDO, H. et al. (2014): «El arte rupestre esquemático del Arroyo Barbaón (Parque Nacional de Monfragüe, Cáceres): contextualización arqueológica y caracterización de pigmentos», Zephyrus, n 74, pp. 15-39.

CORRALIZA, J.A. et al. (2002): Los Parques Naturales en España: conservación y disfrute. Madrid, Fundación Alfonso Martínez Escudero y Ediciones Mundi-Prensa S.A., $491 \mathrm{pp}$.

DELGADILLO MACÍAS, J. (2006): «Dimensiones territoriales del desarrollo rural en América Latina», Problemas del Desarrollo, vol. 37 (144). pp. 97-120.

FERIA TORIBIO, J.M. (2013): «El patrimonio territorial: Algunas aportaciones para su entendimiento y puesta en valor», e-rph. Revista Electrónica de Patrimonio Histórico, $\mathrm{n}^{\circ} 12$, pp. 200-224.

COTEC (2010): Innovación en el Sector del Patrimonio Histórico. Informes sobre el sistema español de innovación para la innovación tecnológica. Madrid, Fundación Cotec para la Innovación Tecnológica, 13 pp.

GARCÍA MARÍN, R. (2011): «Turismo y desarrollo rural en la comarca del Noroeste de la Región de Murcia: Los programas europeos Leader», Cuadernos de Turismo, $\mathrm{n}^{\circ}$ 27, pp. 419-435.

GARCÍA ZARZA, E. (1977): «Evolución, estructura y otros aspectos de la población cacereña», Revista de Estudios Extremeños, vol. 33 (1), pp. 69-144.

GIL MESEGUER, E., BERNABÉ CRESPO, M.B. y GÓMEZ ESPÍN, J.M. (2020): «El Campo de Murcia, un territorio de baja densidad de población en el Sureste de España», Cuadernos Geográficos, vol. 59 (2), pp. 53-72.

GÓMEZ LIMÓN, J. y GARCÍA, D. (2014): Capacidad de acogida de uso público en los espacios naturales protegidos. Madrid, Organismo Autónomo de Parques Nacionales.

GÓMEZ LIMÓN, J. y MÚGICA DE LA GUERRA, M. (2007): «Estrategias sostenibles en los destinos naturales: La implantación de la Carta Europea de Turismo Sostenible en espacios naturales protegidos», Estudios Turísticos, n $172-173$, pp. 233-239.

GURRÍA GASCÓN, J. L. (1981): «Robledillo de Gata: un asilo natural de ancianos», Norba, $\mathrm{n}^{\circ} 2$, pp. 117-128.

GURRÍA GASCÓN, J.L., NIETO MASOT, A. y HERNÁNDEZ CARRETERO, A. (2009): «Población, actividad y paro en la segunda mitad del siglo XX en Extremadura», Tejuelo: Didáctica de la Lengua y la Literatura. Educación, nº 6, pp. 82-103.

GURRÍA GASCÓN, J.L., NIETO MASOT, A. y HERNÁNDEZ CARRETERO, A. (2011): «Las rentas agrarias y rurales en Extremadura», Geographicalia, $\mathrm{n}^{\circ}$ 59-60, pp. 151-164.

HERNÁNDEZ HERNÁNDEZ, M. (2009): «El paisaje como seña de identidad territorial: valorización social y factor de desarrollo, ¿utopía o realidad?», Boletín de la Asociación de Geógrafos Españoles, n 49, pp. 169-183.

HIDALGO-FERNÁNDEZ, A. et al. (2013): «Estimación del valor económico de La Sierrezuela y Los Villares», Cuadernos Geográficos, nº 52 (1), pp. 178-204. 
HUMMEL, B.G. (2001): «Posibilidades en comunidad: lecciones aprendidas en Maquin», en Rodríguez, F. (Ed.) Manual de Desarrollo Local. Gijón, Universidad de Oviedo, CeCodet y Trea, pp. 431-444.

INSTITUTO NACIONAL DE ESTADÍSTICA (INE): https://www.ine.es/.

INSTITUTO DE ESTADÍSTICA DE EXTREMADURA: https://ciudadano.gobex.es/web/ ieex/ieex).

JUNTA DE EXTREMADURA (2019): Atlas Socioeconómico de Extremadura. Mérida, Instituto de Estadística de Extremadura.

JURADO ALMONTE, J.M. y PAZOS-GARCÍA, F.J. (2016): «Población y turismo rural en territorios de baja densidad demográfica en España», Boletín de la Asociación de Geógrafos Españoles, $\mathrm{n}^{\circ}$ 71, pp. 247-272.

KERLINGER, F. y LEE, H. (2002): Investigación del comportamiento. México, McGraw Hill/ Interamericana.

LAVIANCA, M. y NAVARRO VALVERDE, F. (2019): «Depopulation and aging in rural áreas in the European Union: practices starting from the LEADER approach», en Cejudo, E. y Navarro, F. (Eds.) Despoblación y transformaciones sociodemográficas de los territorios rurales: los casos de España, Italia y Francia. Università de Salento. Perspectives on Rural Development, $\mathrm{n}^{\circ} 3$, pp. 223-252.

LECO BERROCAL, F. et al. (2010): Reserva Mundial de la Biosfera de Monfragüe. Aproximación Goegráfica y visión cartográfica. Cáceres. Ministerio de Medio Ambiente y Medio Rural y Marino.

LECO BERROCAL, F., PÉREZ DÍAZ, A. y MATEOS RODRÍGUEZ, A.B. (2012): «Análisis del capital social, la gobernanza y el desarrollo territorial en el Parque Nacional Monfragüe y la Reserva Natural Garganta de los Infiernos», en Foronda Robles, C. (Coord.) Capital social en espacios naturales protegidos, Ulzama Ediciones, pp. 259325.

LECO BERROCAL, F, PÉREZ DÍAZ, A. y MATEOS RODRÍGUEZ, A.B. (2013): «Uso público y capacidad de carga perceptual en espacios naturales protegidos», Papeles de Geografía, $\mathrm{n}^{\circ}$ 57-58, pp. 127-144.

LECO BERROCAL, F., MATEOS RODRÍGUEZ, A.B. y PÉREZ DÍAZ, A. (2015): «Estudio de la demanda del turismo en el Parque Nacional y Reserva de la Biosfera de Monfragüe», Cuadernos de Turismo, nº 35, pp. 231-257.

LECO BERROCAL, F., PÉREZ DÍAZ, A. y MATEOS RODRÍGUEZ, A.B. (2017): «Crisis demográfica en la Extremadura rural: valoración a través de los Grupos de Acción Local (2007-2014)», Cuadernos Geográficos, vol. 56 (1), pp. 76-100.

LOSCERTALES, B. (1999): «El turismo rural como forma de desarrollo sostenible. El caso de Aragón», Geographicalia, $\mathrm{n}^{\circ} 37,15 \mathrm{pp}$.

MAROTO MARTOS, J.C. y PINOS NAVARRETE, A. (2019): «¿El turismo rural freno de la despoblación? El caso del sur de España», en Cejudo, E. y Navarro, F. (Eds.) Despoblación y transformaciones sociodemográficas de los territorios rurales: los casos de España, Italia y Francia. Università de Salento. Perspectives on Rural Development, $\mathrm{n}^{\mathrm{o}} 3$, pp. 328-374. 
MATA OLMO, R. (2008): «El paisaje, patrimonio y recurso para el desarrollo territorial sostenible: Conocimiento y acción pública», Arbor, Ciencia, Pensamiento y Cultura, $\mathrm{n}^{\mathrm{o}} 729$, pp. $155-172$.

McMANUS, P. et al. (2012): «Rural community and rural resilience: What is important to farmers in keeping their country towns alive?», Journal of Rural Studies, vol. 28 (1), pp. 20-29.

MOLINERO, F. (2019): «El espacio rural de España: evolución, delimitación y clasificación», Cuadernos Geográficos, nº 58 (3), pp. 19-56.

MUÑOZ FLORES, J. C. (2008): «El turismo en los espacios naturales protegidos españoles, algo más que una moda reciente», Boletín de la Asociación de Geógrafos Españoles, $\mathrm{n}^{\circ}$ 46, pp. 291-304.

NIETO MASOT, A. y GURRÍA GASCÓN, J.L. (2005): «Análisis de la población de los programas de desarrollo rural en Extremadura mediante sistemas de información geográfica», Cuadernos Geográficos, vol. 36 (1), pp. 479-496.

NIETO MASOT, A. y CÁRDENAS ALONSO, G. (2015): «El método Leader como política de desarrollo rural en Extremadura en los últimos 20 años (1991-2013) », Boletín de la Asociación de Geógrafos Españoles, $\mathrm{n}^{\circ}$ 69, pp. 139-162.

NIETO MASOT, A. y CÁRDENAS ALONSO, G. (2017): «25 Años de políticas europeas en Extremadura: turismo rural y método LEADER», Cuadernos de Turismo, n 39, pp. 389-416.

OBSERVATORIO DE TURISMO DE EXTREMADURA: https://www.turismoextremadura.com/es/pie/observatorio.html

O'REILLY, A.M. (1986): «Tourism carrying capacity: concepts and issues», Tourism Management, $\mathrm{n}^{\mathrm{o}} 7$ (4), pp. 254-258.

OCDE (2006): El nuevo paradigma rural: políticas y gobernanza. Madrid, Ministerio de Agricultura, Pesca y Alimentación.

PASCUAL, J.A. (2007): La gestión del uso público en espacios naturales. Madrid, Miraguano.

PÉREZ DÍAZ, A. (1988): «Extremadura entre la emigración y el retorno», Alcántara, $\mathrm{n}^{\circ}$ 13-14, pp. 255-284.

PÉREZ DÍAZ, A.; LECO BERROCAL, F. y BARRIENTOS ALFAGEME, G. (2012): Población y despoblación en Extremadura. Cáceres, Gobierno de ExtremaduraFEDER, $240 \mathrm{pp}$.

PLUMMER, R. y ARMITAGE, D. (2007): «A resilience-based framework for evaluating adaptive co-management: Linking ecology, economics and society in a complex world», Ecological Economics, vol. 61 (1), pp. 62-74.

RENGIFO GALLEGO, J.I. y SÁNCHEZ MARTÍN, J.M. (2019): «La repercusión turística de la declaración de Monfragüe como Parque Nacional», Cuadernos Geográficos, vol. 58 (1), pp. 121-140.

RODRÍGUEZ RODRÍGUEZ, D., LARRUBIA, R. y SINOGA, J.D. (2021): «Are protected areas good for the human species? Effects of protected areas on rural depopulation in Spain», Science of The Total Environment, vol. 763, 144399. 
SÁNCHEZ SÁNCHEZ, F.J. y SÁNCHEZ, A.M. (2018): «Impacto del turismo rural sobre el empleo en España: una aproximación a escala provincial», Cuadernos de Desarrollo Rural, vol. 15 (82), pp. 19-37.

SANTOS GONZÁLEZ, J. y REDONDO VEGA, J.M. (2016): «Gestión, protección y despoblación en las Reservas de la Biosfera de la Cordillera Cantábrica», Pirineos, $\mathrm{n}^{\circ} 171,25 \mathrm{pp}$.

SERRANO GIL, Ó. (2016): «Aspectos territoriales y demográficos de la Red de Espacios Naturales Protegidos de Castilla-La Mancha: 1978-2014», Anales de Geografía de la Universidad Complutense, vol. 36 (1), pp. 149-171.

SERRANO MARTÍNEZ, J.M. y GARCÍA MARÍN, R. (2013): «Regresión demográfica en España: crisis económica y cambio de ciclo migratorio», Papeles de Población, vol. 19 (76), pp. 89-128.

SHELBY, B. y HEBERLEIN, T.A. (1986): Social carrying capacity in recreation settings. Oregon State University Press.

SILVA PÉREZ, R. y FERNÁNDEZ SALINAS, V. (2017): «El nuevo paradigma del patrimonio y su consideración con los paisajes: Conceptos, métodos y prospectivas», Documents d'Anàlisi Geogràfica, vol. 63 (1), pp. 129-151.

SOTELO NAVALPOTRO, J.A. (2006): «Instrumentos para el estudio del medio ambiente: métodos para la valoración del coste ambiental», Estudios Geográficos, n 260, pp. 231-258.

SOTO BAQUERO, F., BEDUSCHI FILHO, L.C. y FALCONI, C. (2007): Desarrollo territorial rural. Análisis de experiencias en Brasil, Chile y México. Santiago de Chile, Oficina Regional de la FAO para América Latina y El Caribe, 290 pp.

SOWMAN, M.R. (1987): «A procedure for asseissing recreational carrying capacity of coastal resort areas», Landscape and Urban Planning, vol. 14, pp. 331-334.

TRILLO SANTAMARÍA, J.M. y PAÜL i CARRIL, V. (2018): «La Reserva de la Biosfera Meseta Ibérica como espacio natural protegido transfronterizo: ¿herramienta de conservación o marca promocional?», Documents D’anàlisi Geogràfica, vol. 64 (3), pp. 493-508.

VACAS GUERRERO, T. (2001): «Los espacios naturales protegidos como recurso turístico: metodología para el estudio del Parque Nacional de Sierra Nevada», Estudios Turísticos, $\mathrm{n}^{\circ} 147$, pp. 57-84.

VERA REBOLLO, J.F. y ESPEJO MARÍN, C. (2006): «El papel de los instrumentos de planificación en las dinámicas productivas y territoriales: las directrices y el Plan de Ordenación del Litoral de la Región de Murcia», en Romero, J. y Farinós, J. (Eds.) Gobernanza territorial en España: claroscuros de un proceso a partir del estudio de casos. València. Publicacions de la Universitat de València, pp. 61-79.

WALKER, B., HOLLING, C.S., CARPENTER, S.R. y KINZIG, A. (2004): «Resilience, adaptability and transformability in social-ecological systems», Ecology and Society, vol. 9 (2), 5 pp.

WILSON, G. (2010): «Multifunctional ‘quality' and rural community resilience», Transactions of The Institute of British Geographers, vol. 35 (3), pp. 364-381. 